\title{
FY 91 ANNUAL RESEARCH PLAN
}

December 1990

Work Performed Under Cooperative Agreement No. DE-FC22-83FE60149

Prepared for

U.S. Department of Energy

Assistant Secretary for Fossil Energy

\author{
Bartlesville Project Office \\ P.O. Box 1398 \\ Bartlesville, OK 74005
}

Prepared by

IIT Research Institute

National Institute for Petroleum and Energv Research

P.O. Box 2128

Bartlesville, OK 74005

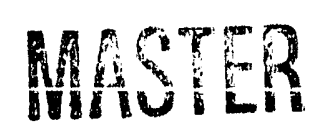




\section{FOREWORD}

The National Institute for Petroleum and Energy Research (NIPER) is pleased to submit the "FY91 Annual Research Plan," NIPER-465, in accordance with the provisions of Cooperative Agreement DE-FC22-83FE60149 between the IIT Research Institute and the Department of Energy (DOE). Previous research plans have been prepared as follows:

"1983-84 Annual Research Plan," NIPER-6 (NTIS No. DE84010565), May 1984.

"FY85 Annual Research Plan," NIPER-11 (NTIS No. DE85027426), March 1985.

"FY86 Annual Research Plan," NIPER-85 (NTIS No. DE85000143), October 1985.

"FY87 Annual Research Plan," NIPER-164 (NTIS No. DE86000303), October 1986.

"FY88 Annual Research Plan," NIPER-260 (NTIS No. DE8700126), October 1987.

"FY8.9 Annual Research Plan," NIPER-357 (NTIS No. DE89000701), December 1988.

"FY90 Annual Research Plan," NIPER-420 (NTIS No. DE9000210), January 1990.

Annual Reports have also been published als:

"1984 Annual Report: Naticnal Institute for Petroleum and Energy Research," NIPER-20 (NTIS No. DE85000122), April 1985.

"1985 Annual Report: National Institute for Petroleum and Energy Research," NIPER-120 (NTIS No. DE86000265), March 1986.

"1986 Annual Report: National Institute for Petroleum and Energy Research," NIPER-220 (NTIS No. DE87001228), March 1987.

"1987 Annual Report: National Institute for Petroleum and Energy Research," NIPER-320 (NTIS No. DE88001234), October 1988.

"1988 Annual Report: National Institute for Petroleum and Energy Research," NIPER-400

(NTIS No. DE89000759), September 1989.

These plans and reports describe the initiation and development of the research effort at NIPER, and much of that explanation has been left out of this report.

This elghth plan describes the work to be performed in FY91. Projects in both Energy Production Research and Fuels Research are presented in the program.

We wish to express our appreciation to the Director, Project Managers, and other personnel of the DOE/Bartlesville Project Office for their cooperation in the preparation of this plan. 


\section{EXECUTIVE SUMMARY}

In line with the Federal Oil Research Program to maximize the economic producibility of the domestic oil resource, the National Institute for Petroleum and Energy Research (NIPER) presents this FY91 Annual Research Plan, which is designed to help the Department of Energy (DOE) meet the following objectives:

- For the near-ierm, to preserve access to petroleum reservoirs with high potential which are rapidly approaching their economic limits.

- For the near-term, develop analytical and physical property data in heavier feedstocks.

- For the near-term, to develop, test, and help transfer the results of the research to petroleum producers/refiners.

- For the mid- and long-term, to develop and improve the understanding of advanced and novel petroleum recovery processes and process applications for heavier feedstocks.

This Annual Research Plan describes the work to be performed in FY91 for the Depariment of Energy under provisions of the Base Program in Cooperative Agreement DE-FC2283FE60149 between the DOE and IIT Research Institute which operates NIPER.

\section{Oroanlzatlon and Facillites}

NIPER is organized into two research departments -- Energy Production Research (EPR) and Fuels Research (FR). Projects in EPR deal with various aspects of enhanced oil recovery and include reservoir characterization, chernical flocding, gas injection, steam injection, microbial enhanced oil recovery, and the environmental concerns related to these processes. Projects in FR consider the impact of heavy oil and alternative fuels on the processing and end-use of fuels. This breadth of interest assures that NIPER"s work will be significant in advancing petroleum technology and that NIPER, with its staff of about 175 employees, will be a viable place to conduct research for other government agencies and industrial clients.

\section{Besearch Program}

Program planning is the result of a cooperative effort by NIPER employees and BPO project managers. In FY91, the DOE will fund this work through its Enhanced Oil Recovery (EOR) and Advanced Extraction and Process Technology (AEPT) Research Programs. The Base Program accommudates 14 researcin projects. Of this total, EPR has 12 projects and FR has two. The projects are listed in the following table. The Base Program reflects a strong emphasis on enhanced oil recovery (geosaience and recovery processes) while maintaining an interest in basic 
research on the chemistry of crude oils. It is designed primarily for near- and mid-term contributions to the maintenance of the Nation's energy supply.

\section{Eneray Production Besearch}

Research in the Base Program addresses the remaining oil resource with research on reservoir engineering, geology, geophysics, geochemistry, oil recovery processes, and environmental science directed toward the goal of increasing economic produclbility of petroleum resources.

This research program is mission-oriented, with well-defined goals and objectives specified to meet them. Each project within the program addresses the mission. The research clearly addresses the near- and mid-term needs of the petroleum industry, complementing the program's historical emphasis on long-term research. The program reflects the Nation's concern for the environment. The results of the research will be compiled, analyzed, and submitted to the DOE in a timely manner and suitable for dissemination to the private sector.

The EPR program seeks to improve the integration and coordination of geoscience and extraction research, to improve near-term measures to enhance domestic producibility, and to broaden the context of oil recovery research by addressing mobile as well as immobile oil.

\section{Euels Research}

Research in the Base Program recognizes the need to develop both a basic chemical understanding and basic thermochemical and thermophysical properties data to effectively utilize future resources for transportation fuels. Current refineries are more than $90 \%$ efficient when processing light, sweet crudes. This is not the case when processing heavier crudes with higher metals and heteroatom conteni.

This research effort has defined intermediate goals of developing information on compound types in the heavy feedstocks that are most likely to cause problems in the refining sequence or in the finished fuel performance.

The Fuels Research program seeks to broaden the pool of crudes for the refineries while helping to increase the efficiency of introducing heavy crudes to the process stream. 


\begin{tabular}{|c|c|c|c|c|}
\hline \multicolumn{2}{|l|}{ Project } & $\begin{array}{l}\text { DOE FE } \\
\text { Program" }\end{array}$ & $\begin{array}{l}\text { Manpower, } \\
\text { Man-Years }\end{array}$ & $\begin{array}{l}\text { Funding, } \\
\$ K\end{array}$ \\
\hline ENEBGY & PRODUCTION RESEARCH & & & \\
\hline $\begin{array}{l}\text { BE1. } \\
\text { BE2. } \\
\text { BE3. } \\
\text { BE4A. } \\
\text { BE4B. } \\
\text { BE4C. } \\
\text { BE5A. } \\
\text { BE5B. } \\
\text { BE9. } \\
\text { BE11A. } \\
\text { BE11B. } \\
\text { BE12. }\end{array}$ & $\begin{array}{l}\text { Reservoir Assessment and Characterization } \\
\text { TORIS Research Support } \\
\text { Development of Improved Microbial Flooding Methods } \\
\text { Development of Improved Surfactant Flooding Methods } \\
\text { Development of Improved Alkaline Flooding Methods } \\
\text { Development of Improved Mobility Control Methods } \\
\text { Gas Flooding } \\
\text { Mobility-Control and Sweep Improvement in Gas } \\
\text { Flooding } \\
\text { Three-Phase Relative Permeability } \\
\text { Thermal Processes for Light Oil Recovery } \\
\text { Thermal Processes for Heavy Oil Recovery } \\
\text { Imaging Techniques Applied to the Study of Fluids } \\
\text { in Porous Media } \\
\text { Total EPR Base Projects } \\
\text { RESEARCH } \\
\text { Development of Analytical Methodology for Analysis } \\
\text { of Heavy Crudes } \\
\text { Thermochemistry and Thermophysical Properties of } \\
\text { Organic Nitrogen- and Diheteroatom-Containing } \\
\text { Compounds } \\
\text { Total FR Base Projects } \\
\text { TOTAL BASE PROJECTS }\end{array}$ & $\begin{array}{l}\text { EOR-LO } \\
\text { EOR-LO } \\
\text { EOR-LO } \\
\text { EOR-LO } \\
\text { EOR-HO } \\
\text { EOR-LO } \\
\text { EOR-LO } \\
\text { EOR-LO } \\
\text { EOR-LO } \\
\text { EOR-LO } \\
\text { EOR-HO } \\
\text { AEPT }\end{array}$ & $\begin{array}{l}5.8 \\
3.1 \\
2.9 \\
4.8 \\
1.0 \\
1.25 \\
1.2 \\
\\
3.2 \\
3.1 \\
1.95 \\
1.4 \\
3.7 \\
33.4\end{array}$ & $\begin{array}{r}800 \\
340 \\
300 \\
600 \\
150 \\
200 \\
200 \\
\\
440 \\
300 \\
300 \\
250 \\
545 \\
4,425\end{array}$ \\
\hline
\end{tabular}

- Abbreviations: $E O R=$ Enhanced Oil Recovery; LO $=$ Light Oil; $H O=$ Heavy Oil; $A E P T=$ Advanced Extraction and Process Technology 
TABLE OF CONTENTS

Page

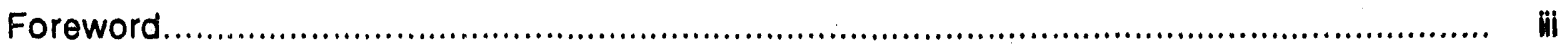

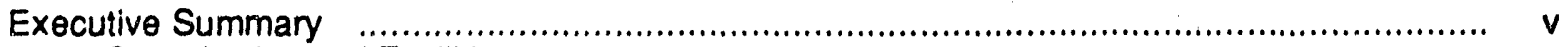

Organization and Facilities ...................................................................................... v

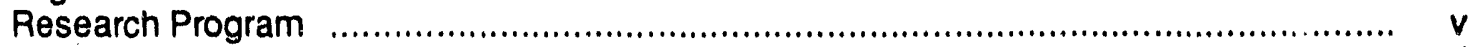

Energy Production Research .............................................................................. vi

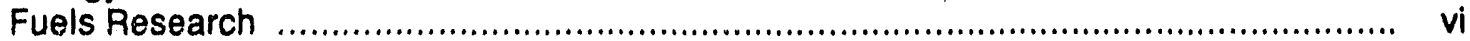

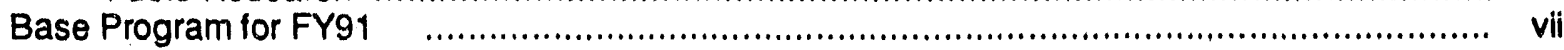

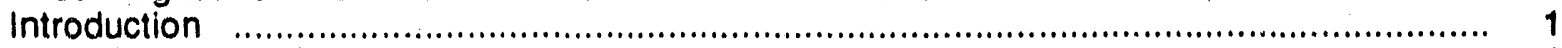

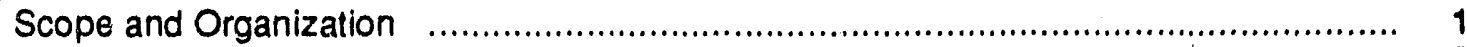

Facilities and Personnel .................................................................................... 2

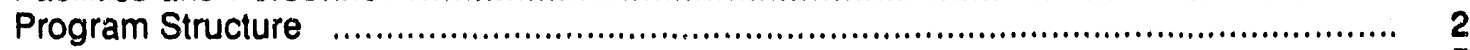

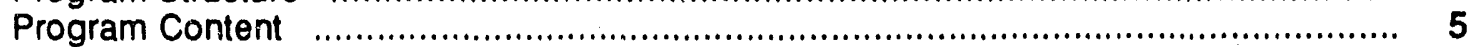

Energy Production Research ................................................................ 6

Fuels Research ....................................................................................... 6

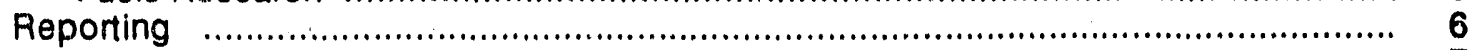

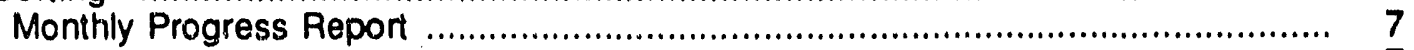

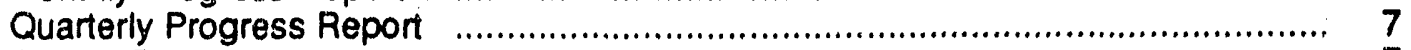

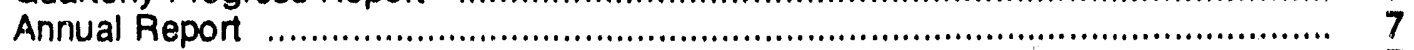

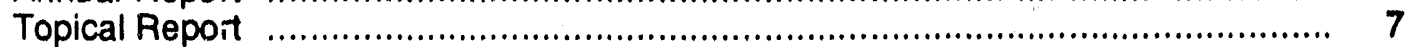

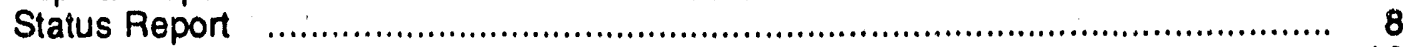

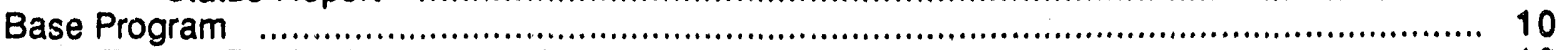

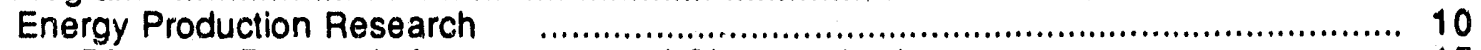

BE1. Reservoir Assessment and Characterization....................................... 15

BE2. TORIS Research Support ............................................................ 19

BE3. Development of Improved Microbial Flooding Methods............................. 22

BE4A. Development of Improved Surfactant Flooding Methods............................ 27

BE4B. Development of Improved Alkaline Flooding Methods............................... 33

BE4C. Development of Improved Mobility-Control Methods................................ 35

BE5A. Gas Flooding........................................................................... 39

BE5B. Mobility Control and Sweep Improvement in Gas Flooding........................ 43

BE9. Three-Phase Relative Permeability Ressarch......................................... 50

BE11A. Thermal Processes For Light Oll Recovery........................................... 55

BE11B. Thermal Processes For Heavy Oil Recovery.......................................... 59

BE12. Imaging Techniques Applied to the Study of Fluids in Porous Media......... 62

Fuels Research............................................................................................. 67

BFR2. Development of Analytical Methodology for Analysis of Heavy Crudes........ 68

BFR3. Thermochemistry and Thermophysical Properties of Organic Nitrogen-

Exhibit 1 and Diheteroatom-Containing Compounds........................................... 74

Appendix A. Capital Equipment Requirements ............................................................... 79

\section{TABLES}

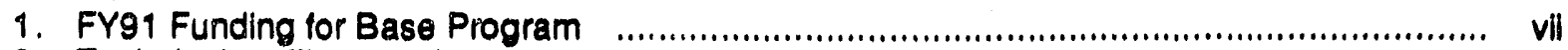

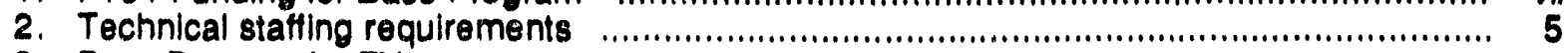

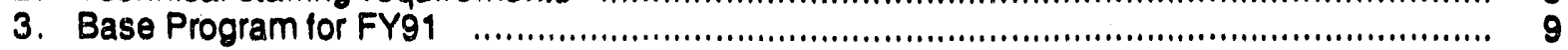

\section{ILLUSTRATIONS}

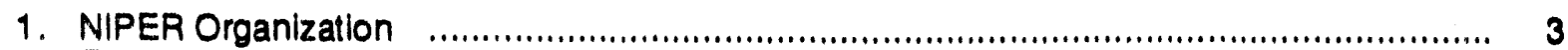

2. Energy Production Research Integrated Base Program ....................................... 11

3. NIPER's Rock-Fluld Imaging Concept...................................................................... 13 


\section{INTRODUCTION}

This is the eighth Annual Research Plan for the National Institute for Petroleum and Energy Research (NIPER). NIPER is operated under a cooperative agreement between the U.S. Department of Energy (DOE) and the IIT Research Institute (IITRI). The cooperative agreement, which became effective October 1, 1983, provides for operation of NIPER as a not-for-profit organization doing research both for the Government and for private companies.

NIPER was established by the DOE to undertake long-range, high-risk research that companies are reluctant to do and to perform contract research for government and industrial clients. This arrangement has enabled NIPER to grow as an independent entity.

The near-term objective of the DOE program is to maintain access to resources presently being produced in domestic oil and gas fields and to decrease the rate of decline of domestic production through the application of current technology. NIPER projects in integrated reservoir characterization, chemical flooding, gas injection, steam injection, and microbial EOR address near-term concerns of domestic oil production. Further, problems associated with the utilization of heavier fossil feedstocks are being addressed as new fuel blends increasingly enter the marketplace. In the near-term, NIPER is uniquely positioned to test new oil and gas technology through industry participation in the Work for Others Program and in government-industry R\&D programs.

The near to mid-term objectives of the DOE program are to maximize the recovery efficiency of discovered oil and gas through improved understanding of the resource, to develop advanced extraction and instrumentation techniques, and to work closely with oil producers through DOEsponsored technology transfer programs. The objective also emphasizes an expanded understanding of the environment, assuring that it keeps pace with new and improved extraction technologies. NIPER projects dealing with the quantification of reservoir heterogeneities, pore structure analysis, and fluid flow in porous media are designed to improve extraction technologles. Current advances in instrumentation and simulation procedures can be expanded to enhance the discovery and ultimate utilization of both conventional and unconventional resource targets. The NIPER program will assist DOE in its evaluation of the environmental impact on new petroleum exploration and production technologles.

\section{Scopa and Oroanlzation}

Research at NIPER is broad in scope and provides for major studies in petroleum and fuels research. The DOE-sponsored projects described in this research plan form the nucleus which enables NIPER to present a broad capability of research for other agencies and private companies. NIPER is engaged in active marketing to offer these opportunities to a wide clientele and, in so doing, has achieved significant success. 
The organization at NIPER is shown in figure 1. The research effort is divided between two departments: Energy Production Research (EPR) and Fuels Research (FR). The EPR Department has primary responsibility for enhanced oil recovery projects and is divided into three sections: Geotechnology, Chemical and Microbial Displacement, and Thermal and Gas Displacement. The FR Department is divided into Processing and Thermodynamics, Fuel Chemistry, and Fuels/Engines Sections.

The Bartlesville Project Office (BPO) is collocated with NIPER and serves as the DOE administrator of the cooperative agreement. The BPO is delegated the lead assignment for implementing Fossil Energy programs in Enhanced Oil Recovery (EOR) and Advanced Extraction and Process Technology (AEPT). These programs are carried out by BPO personnel through management of a number of Fossil Energy projects executed by (1) NIPER, which utilizes the Federal equipment and facilities at Bartlesville, (2) industrial and university research organizations, and (3) National Laboratories.

\section{Eacillties and Personnel}

NIPER's facilities are located in Bartlesville, Oklahoma, and consist of 19 buildings with a total floor space of 156,000 square feet on 17 acres. Many of the buildings were specifically designed for petroleum research activities.

NIPER has a staff of approximately 175 people with over 90 technically trained scientists and engineers having background experience and competence in most areas of petroleum research and technology transfer. Major areas of strength are enhanced oil recovery, geoscience, hydrocarbon processing, fuel characterization, mass spectiometry, thermodynamics, and fuels/engines research.

Equipment available at NIPER includes both state-of-the-art commercial equipment and inhouse-developed items that may be prototypes of research equipment for commercial development. New capital equipment is added to keep abreast of improved methods and to try new approaches. The capital equipment proposed for FY91 is listed in appendix $A$.

Another important part of NIPER is its specialized library with excellent coverage on petroleum and related topics. On-line computer data files, such as the DOE Energy Data Base (RECON) and commercial services, are used. Interlibrary loan facilities extend the capability even further. 
NATIONAL INSTITUTE FOR

PETROLEUM AND ENERGY RESEARCH

ORGANIZATION

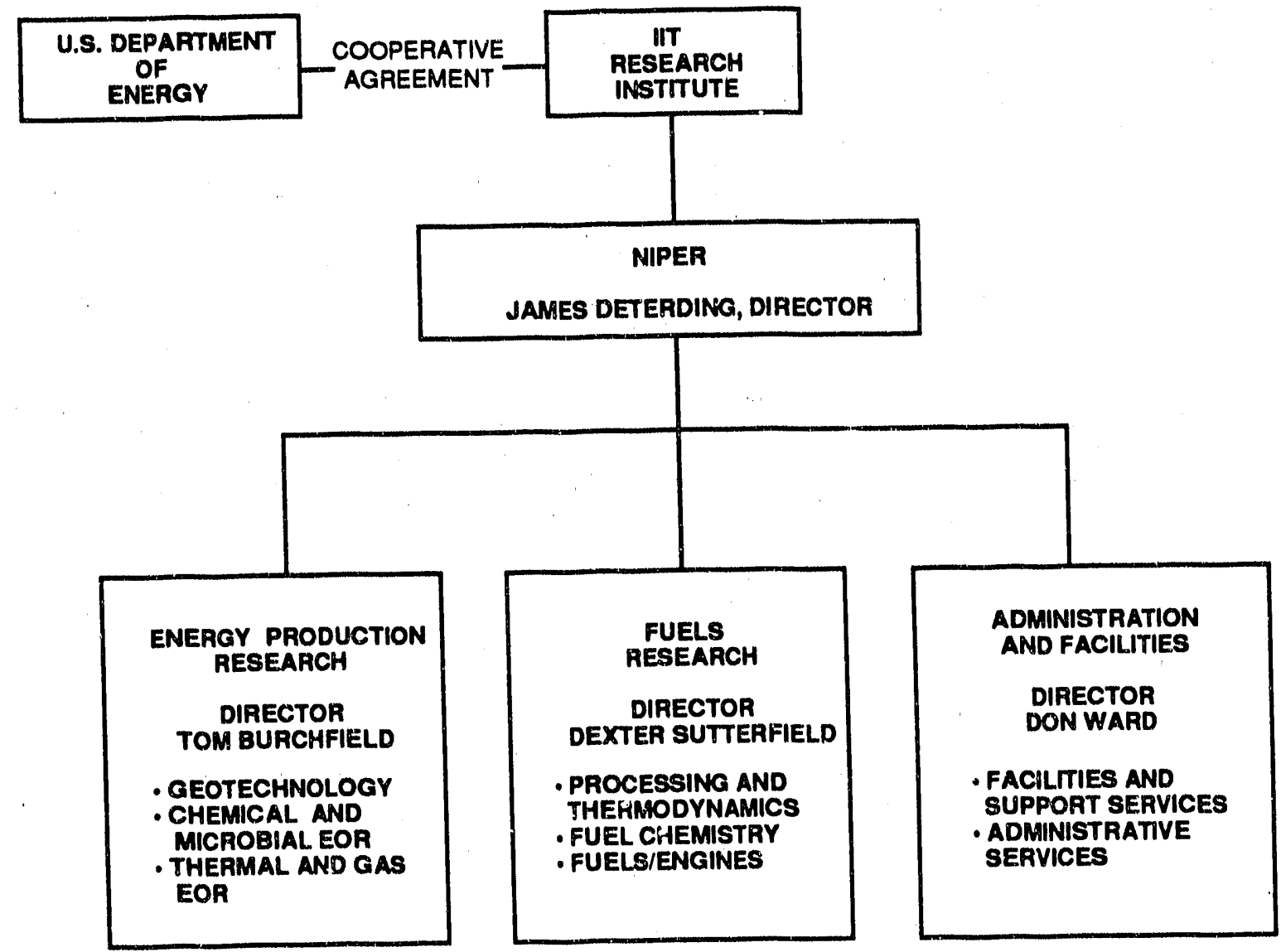

FIGURE 1. - NIPER Organization. 


\section{Prearam Structure}

Under the cooperative agreement, NIPER's research program consists of three elements. The Base Program is specifically designed to assist the DOE in meeting its objectives through EOR processes and geoscience research and fundamental studies for the conversion of available hydrocarbons to quality transportation fuels. The second segment is the Supplemental Government Program, and it includes research for non-DOE government agencies as well as DOE work not included in the Base Program. The third segment is the Work for Others Program which encourages research work from the private sector and others. Only the Base Program is included in this plan.

The numbering system for the project descriptions consists of: a letter (B) indicating the Base Program, a letter designation for the Research Group (E for Energy Production Research and FR for Fuels Research), and a numeral indicating the project number. Thus, BE3 would indicate project 3 of Energy Production Research. The numbers are not consecutive because some projects have been completed and their numbers are not reassigned to new projects.

The projects in the Base Program are described under the following headings:

(1) Background--history of problem, need for research, connection with DOE goals, previous work.

(2) Objective--a brief statement of project goals.

(3) Scope of Work--approach, tools, and techniques so be used. Includes a listing of specific tasks to be performed.

(4) Deliverables-ureports to be submitted to DOE.

(5) Planned Staffing--listing of positions by categories and marn-years. Project Leaders are named.

(6) Equipment Requirements--major items of equipment needed for the project indicating whether they are available or will have to be purchasod.

The funding for the Base Program is $\$ 5.075$ million, distributed as shown in table 1. The Base Program provides for technical staffing requirements of 37.8 man-years, as shown in table 2.

TABLE 1. - FY9o funding for Base Program

\begin{tabular}{lc}
\hline Project Funding & $\begin{array}{c}\text { Base Program } \\
\text { DOE, \$K }\end{array}$ \\
\hline $\begin{array}{l}\text { Energy Production Research } \\
\text { Fuels Research }\end{array}$ & $\begin{array}{r}4,425 \\
650\end{array}$ \\
& Total \\
\hline
\end{tabular}


TABLE 2. - Technical staffing requirements

\begin{tabular}{ll}
\hline Base Program & $\begin{array}{l}\text { Manpower, } \\
\text { man-years }\end{array}$ \\
\hline Energy Production Research & 33.4 \\
Fuels Research & $\frac{4.5}{37.9}$ \\
\hline
\end{tabular}

\section{Program Content}

The Annual Research Plan for NIPER describes projects in the Base Program which are fully funded by DOE. It is designed to support near-, mid-, and long-term DOE programs in enhanced oil recovery and advanced extraction and process technology, with emphasis on near-term (5year) objectives.

For the Base Program, initial guidance in terms of funding profile by work area was given by DOE. Work statements were prepared by NIPER and reviewed by BPO Program Managers and Technical Project Officers and DOE Headquarters Program Managers. Final approval is provided by the Program Guidance Cornmittee. The FY 91 Base Program has been refocused to comply with the objectives of the Federal Oil Research Program Implementation Plan. The new emphases in the Base Program projects are on field work, field support, technology transfer, and synergies among different projects and disciplines. Some projects were continued af,er being scrutinized for agreement with objectives of the Program Implementation Plan.

\section{Energy Production Research}

Base Program research conducted by the Energy Production Research Department (EPR) is designed to improve, in the near-term, the predictability and performance of EOR processes. The program has combined efforts directed at DOE analysis and planning activities, support research, and field work. Previous emphasis on support research should be continued in order for DOE to meet the goals of the Federal Oil Research Program Implementation Plan (PIP). The proposed program parallels the new implementation plan with (1) phased field analysis that identifies near-term opportunities for operators and needs for risk reduction by the federal government for mid-term and long-term opportunities, (2) technology transfer directed toward operators to generate interest in the opportunities identified in the field analysis and supporting research work by NIPER and other organizations, (3) application of technical advances to specific field applications, and (4) continued research directed toward improving the understanding of the mechanisms of EOR processes. 
In this plan, projects are grouped into two major areas of work. The first focuses on improved oil recovery through a better understanding of the basic mechanisms of EOR processes. Physical and mathematical models are developed and used to simulate processes and verify hypotheses. These models also are useful as tools for planning future research. The second major area of work is concerned with quantitative predictions of fluid-flow behavior in reservoirs. Such fluid-flow behavior is affected by the geometry or pores and the reservoir as a whole, wettarility, mineralogy, fluid distribution, permeability, heterogeneities on both micro- and macr scopic scales, and the history of the reservoir.

The Base Program proposed for EPR will continue working toward near- and mid-term goals of improving predictability and performance of EOA processes through integrated studies of fluidflow behavior and process mechanisms. Experimental results will be incorporated into process and reservoir numerical simulators. EPR has a total of 12 projects in the Base Program, 11 of which are funded under DOE's Enhanced Oil Recovery Program and one under the Advanced Extraction and Process Technology Program. The research of BE1 is based on a specific reservoir, while all the others are based on generic reservoir properties and are aimed at producing results usable by domestic producers in the near term.

\section{Fuels Rosearch}

The Flugls Research Department has two Base Program projects in DOE's Advanced Extraction and Process Technology Program. The research effort in project BFR2 will be to develop and refine analytical methods for determining the compounds or types of compounds suspected of contributing to problems associated with refining and product acceptability.

Project BFR3 will be a continuation of the program for determining thermodynamic properties of polycyclic, nitrogen-containing aromatic compounds and other polycyclic aromatics containing two heteroatoms. These areas are selected because refinery feedstocks Increasingly include more heavy oll and are expected to include tar sand bitumen, shale oll, and coal llquils in the future. These materials contain increasing levels of heteroatom-containing constituents.

Fuels Research is working loward the goal of Improving the understanding of upgrading heavy olls and atternatlve feedstocks to reach a theoretical and fundamental background at least equivalent to that presently used in the refining of conventional crude olls.

\section{Beporting}

Reports to the Department of Energy include monthly, quarterly, annual, topical, and status reports. Topical and status reports are identilied in the Deliverables section of the project plans. Toplcal reports may be used as the basis for technical soclety presentations and/or journal publications once they have been submitted to the DOE. 


\section{Monthly Progress Report}

The Momihly Report provides financial data and progress toward key milestones. It is desigitied to be as brief and concise as practical.

Monthly reports for all projects will be delivered to the BPO by the 20 th of the month following the reporting period. The Monthly Report contains a research summary for cach project addressing progress towards key milestones and a key milestone status report showing that work is ahead of schedule, on schedule, or behind schedule. Proposed I medial action and impact on completion of the project will be addressed for work that is behind schediule.

The Morthly Report will give the financial and manpower status for each project and for the cotal Base Program. An updated listing of the status of all key milestones and deliverables will also be included.

\section{Quarterly Technical Report}

Quarteriy Technical Reports are summary presentations of technical progress. They focus on advances made in the techrical program and are limited in the amount of material presented. Whenever a phase of a project indicates the need for a comprehensive description, a topical or status report will be written.

Quarterly Technical Reports are to be delivered to the BPO by the last day of the month following the reporting period. The Quarterly report contains a summary of the technical progress on each project during the reporting period and includes pentinent data, research results, and conclusions.

\section{Annual Report}

The annual report is a summary of technical progress made on each approved research project. It focuses on the advances made in the technical program and is limited in the amoumt of material presented.

The annual report will bo delwered to the BPO 90 days after the end of the fiscal year. The report contains a brief summary (project by project) of the year's research work and ac. complishments.

\section{Toplcal Report}

Completion of a significant phase of the research usualiy results in a topical report. It oncompasses a body of work that completes an assignment (task or tasks) and is a stand-alone document. Otten, it may result in a report to a technical society or lead to pubilcation of a joumal article. 
Topical reports describing work on individual projects are designated throughout the plan as deliverables under the cooperative agreement. Dates shown for thess deliverables in the plan are the daies a final draft of the repon will be submitted to the BPO for review.

\section{Status Report}

Status reports are interim progress reports prepared for DOE Prcject Managers. They have much the same basis as that of topkcal reponts bust represent completion of only a portion of a total research effort. In certain instances, a status report may be only a one or two-page letter summar; If a status report is listed as a deliverable, the designated date refers to the date that the final draft is to be delivered to the BPO.

\section{BASE PROGRAM}

The Base Program--fully funded by DOE for $\$ 5.075$ million-is a research program designed to suppont DOE in its effort to maximize the economic producibility of domestic oil and gas resources through field work, field suppon, technology transfer, geoscience, and EOR research and to determine the processing criterta required in converting available hydrocartons to quality transportation fuels. The Base Program acco.nmodates 14 research projects. Of this total, EPR has 12 projects and FR has two.

As shown in table 3, EPR's 12 projects are funded from DOE's Enhanced Oll Recovery and Advanced Extraction and Process Technology research programs in the amount of $\$ 4,425 \mathrm{~K}$. The two FR projects are funded by Advanced Extraction and Process Technology in the amount of $\$ 650 \mathrm{~K}$, bringing the total program to $\$ 5,075 \mathrm{~K}$. Each of the 14 projects addresses a problem area in the projected future developmem of energy resources in the United States. U. S. proved reserves have declined steadily since the 19708 , and imports already constitute more than $50 \%$ of domestic consumption. To hall this increase in dependence on imported oil, the precipitous abandonment of marginal wells has to be arrested, and promising and advanced techrologies have to be developed and transferred to operators. NIPER's research proyram is structured to achieve these goals.

Enhanced oil recovery projects are conducted by NIPER in its Energy Production Research Department, and projects relating to analysis and properties of alternative fuel sources are conducted in the Fueis Research Department. Together, the two groups of projects represent an effort to develop preparedness for the energy problems which appear inevitable. 


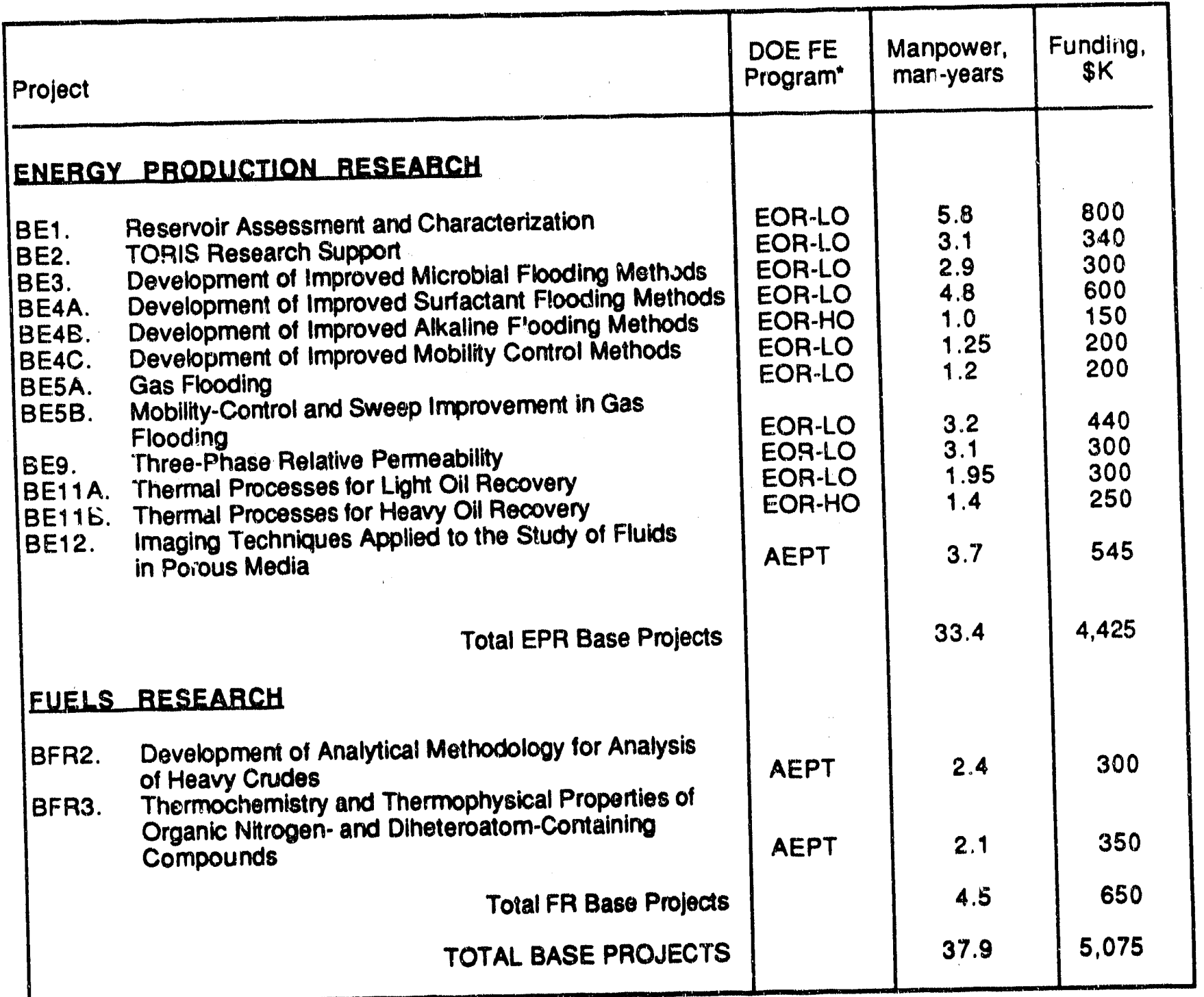

- Abbreviations: EOR - Enhanced Oll Recovery; LO = Light Oil; HO = Heavy Oil; AEPT = Advanced Extraction and Process Technology 


\section{Energy Productlon Research}

Research in the Base Program is designed to support the Federal Oil Research Program as outlined in DOE's Program Plan for Enhanced Oil Recovery. Federal enhanced oil recovery research is a national effort to maximize the econornic producibility of the domestic oil resource. Specifically, the program is designed for the near-tgrm to preserve access to reservoirs with high potential which are rapidly approaching their economic limits; for the mid-term, to develop and transfer advanced oil recovery technologies to operators; and for the long-term, to improve the understanding of oil recovery mechanisms to define new recovery techniques.

The Federal Oil Research Program defines six closely integrated lines of research reflecting the respective EOR processes and the "crosscutting" issues that affect all EOR processes. These are chemical flooding, thermal recovery, gas flooding, microbial EOR, basic geo. science/resource research, and analysis and evaluation.

The Energy Production Research Program has two main parts, as shown in figure 2. The first emphasizes geoscience research, and the second focuses on EOR processes. Results from both parts are combined to develop reservoir and process simulators which are used to predict oil recovery and design EOR projects.

The geoscience research program has combined efforts directed at DOE analysis and planning activities, support research, and field work. The past emphasis on support research should be continued in order for the DOE to meet the goals of the Federal Oil Research Program Implementation Plan (PIP). The proposed NIPER program parallels the new implementation plan with (1) phased field analysis that identifies near-term opportunities for operators and needs for risk reduction by the federal government for mid-term and long-term opportunities, (2) technology transfer directed toward operators to generate interest in the opportunities identified in the field analysis and research support work by NIPER and other organizations, and (3) application of research support technical advances to specific field applications.

Four projects relate to geoscience: BE1 - Assessment and Characterization of Reservoirs, BE2 - TORIS Research Support, BE9 - Three-Phase Relative Permeability, and BE12 - Imaging Techriques Applied to The Study of Fluids in Porous Media. BE1 fits the PIP in the area of supporting research and developrnent directed toward advanced interpretation techniques such as geostatistics, geological scaling and modeling, and integrated interpretation protocols. BE1 also takes advantage of work in other areas such as well testing and reservoir performance simulation. TORIS support in BE2 bring! ogether information from a wide range of activities including the results 


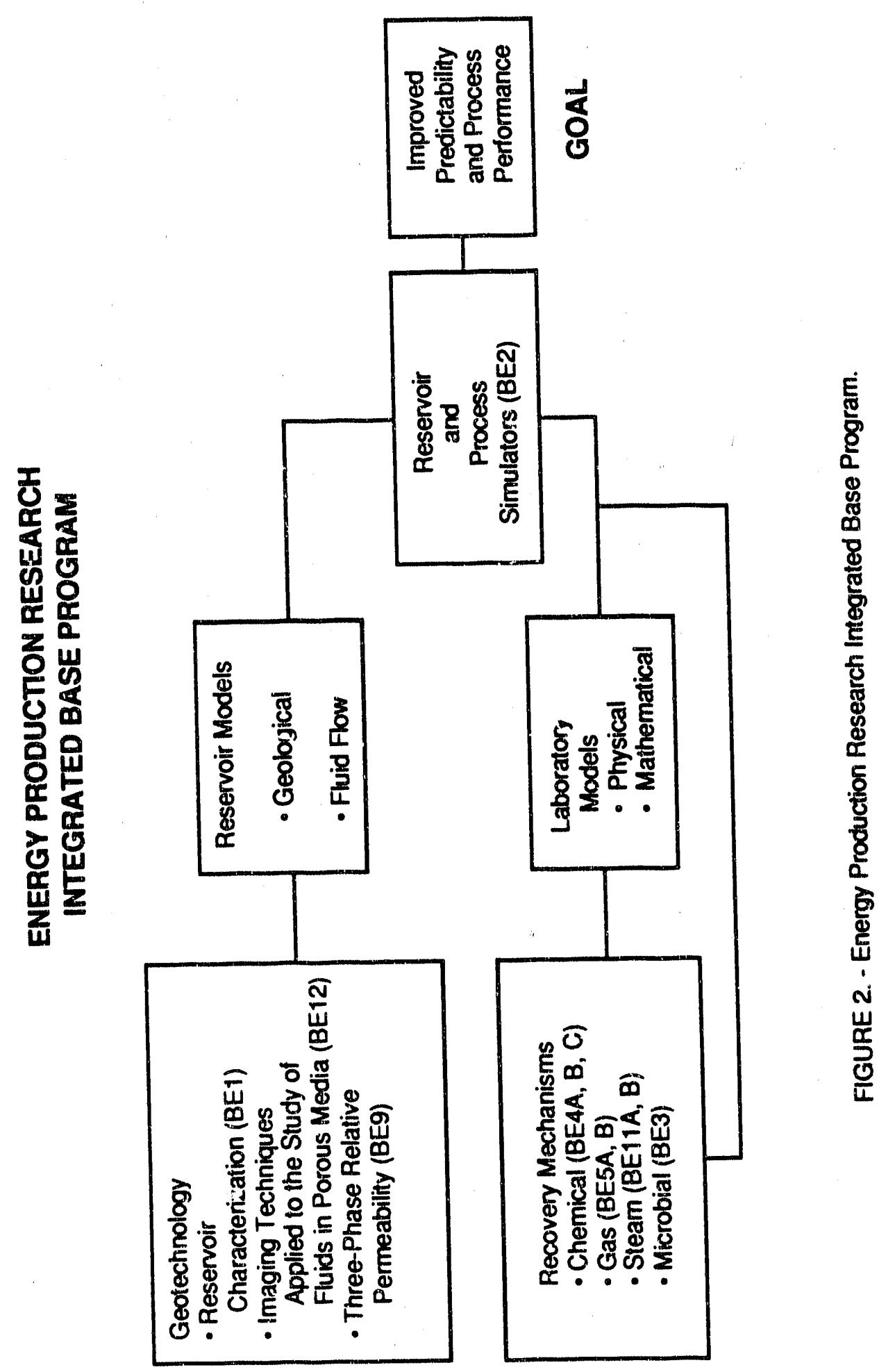


of EOR field projects, reservoir descriptions, the size of the Nation's petroleumi reserves, and reservoir performanse simulation. The work in BE9 relates to supporting research and development in the areas of reservoir chemistry and physics and rock-fluid systems. Since most oil recovery processes involve two- or three-phase flow phenomena, this work relates directly or indirectly to all advanced tertiary recovery research. Finally, work in BE12 is directed toward the development of advanced techniques in the areas of reservoir chemistry and physics and rockfluid systems at the pore and core levels. Since EOR methods are directed toward mobilizing a larger fraction of the oil in place, the results of BE12 will be valuable to other research directed toward each of the specific EOR processes, especially in understanding pore level recovery mechanisms and scaling up from pore level to core level or larger. All of these projects have produced near-term results and have allowed NIPER to assist major and independent oil companies solve real production problems. This interface between DOE-supported research at NIPER and oil companies will continue in FY91. The rock-fluid imaging concept used in BE1, BE9 and $B E 12$ research, and the scaling up of reservoir properties from pore to core to field level is shown in figuie 3.

Chemical flooding processes vre specifically addressed in three Base Program Projects. The effort under project BE4A has been focussed on the structure-property relationships of thirdgeneration, mixed surfactant systems. These mixed systems offer greater flexibility than singlesurfactant systems. In FY91, the study of these systems will be continued. In addition, the application of these and other surfactant systams in near-wellbore cleanup ( to increase injectivity or paraftin removal) will be initiated. These results can be applied to the field in the near-term. In project BE4B, an alkaline-surfactant-polymeP(ASP) process patented by NIPER will be designed for a field in which a pilot lest of the recovery method is being considered. The work in project BE4C is to determine the capability of low-molecular-weight polymer gels for improving mobility control. Studies will be conducted to determine the degree of gel penetration into highly permeable zones as well as the degree of hydrolysis required in making cost-effective polymer gels. The previously developed profile modification simulator will also be used to study the effoct of in-depth treatments and gel treatment strategles on the rate of oil recovery.

Gas flooding research comprises two projects in the Base Program. A task in BE5A will experiment with an effective alternative to foam for $\mathrm{CO}_{2}$ flooding. Success in ihls program would fulfill the near-term objective of the PIP to apply currently defined, advanced EOR technologies in oll fields. Studies on effects of porous media and mass transfer on $\mathrm{CO}_{2}$ phase behavior and the development of an accurate phase behavior prediction package are also planned for this project. This year's proposal in BE5B includes the expansion of capabilities at NIPER to ovaluate foaris 


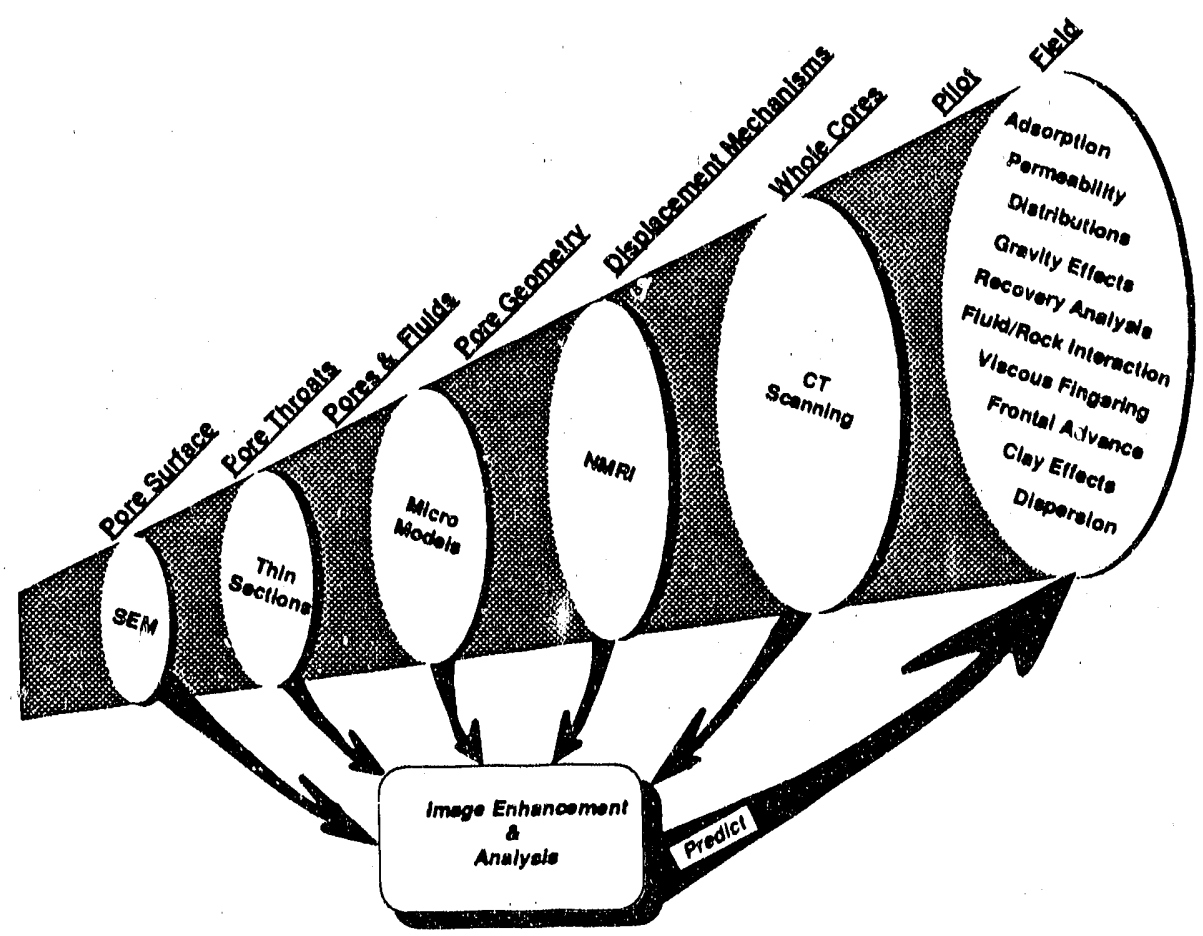

FIGURE 3. - NIPER's rock-fluid imaging concept showing the comparison of imaging technique with the scale being investigated.

under radial flow conditions. In addition to mobility-control studies with foam, an attempt will be made to identify cost-effective entrainers, (hydrocarbon or short chain alcohols that can improve extractability of hydrocarbon in $\mathrm{CO}_{2}$, improve miscibility, and increase $\mathrm{CO}_{2}$ viscosity) for use in $\mathrm{CO}_{2}$ field projects. An effective entrainer would, in the near-term, increase sweep efficiency and displacement efficiency and, therefore, the recovery efficiency of $\mathrm{CO}_{2}$ flooding. Testing the effectiveness of entrainers in cyclic $\mathrm{CO}_{2}$ processes is also planned to fulfill the near-term objective of the PIP.

Research on thermal processes will concentrate on steamflooding, both for light oil recovery (BE11A) and heavy oil recovery (BE11B). A task in BE11A will evaluate the effect of (steam or hot water) temperature on produced oil composition and remaining oil saturation, using Teapot Dome sand and crude oil. Since a steamflood project in this reservoir is currently under way, the results would immediately help those operating the field project to assess their potential recoveries. A task under $B E 11 B$ is to compile a supplement to the steamflood operator guide published in FY 90. This will impact on near-term objectives to transfer thermal technologies from California operators to areas not currently using steamflood operations. These areas include the mid-continent region where heavy oil has been identified as a target for exploitation, but currentiy 
little of it is being produced. Another task is to develop an implicit version of NIPER's numerical laboratorv thermal simulator.

Microbial enhanced oil recovery (MEOR) methods are being developed in project BE3. The primary objectives of this project are to elucidate the recovery mechanisms for MEOR and to provide a scientific basis for the technology. A wo-pronged approach - (1) experimental and (2) simulation - is applied in this project. The experimental program will form the basis for simulator development, and simulation results will provide guidance for further experiments in an attempt to identify mechanisms responsible for recovering oil. Results of this project will be used in designing and operating pilot projects sponsored by DOE.

Complete descriptions of research to be performed under the 12 EPR Base Program projects follow. 


\section{BE1. - RESERVOIR ASSESSMENT AND CHARACTERIZATION}

\section{BACKGROUND}

The broad objectives of the Department of Energy's program for geosclence research are to develop methods for locating residual oil saturation distribution in oll reservolrs and evaluate sultable methuds for recovering the oil. NIPER's spectic objective formulated in the FY86 Annual Research Plan is to develop a better understanding of heterogeneities that influence the movement and trapping of flulds in barrier island/shoreline barrier resenoirs. Shorellne barriers are ranked in the top 10 of priority reservoir geologic classes in the DOE Oll Research Program Implementation Plan.

Heterogeneities that strongly influence the trapping of oll and control its movement in barrier island reservoirs were identified within a selected reservoir (Bell Creek (MT) field). Effects of the heterogeneities were quantified to improve predictions of fluid production from the barrier island/shoreline barrier. Data were collected from outcrops and analyzed for development of a quantified geological model that would incorporate the effects of all the critical geological heterogenelties. Geological and engineering data from the tertiary incentive project (TIP) portion and surrounding areas of Unit $A$ of Bell Creok fleld were used to refine the integrated geologicalengineering model of the reservoir. A second barrier island/shoreline barrier reservolr (Patrick Draw (WY) fleld) was then selected, and analysis was begun to refine the shoreline barrier reservoir description methodology and to quantify the effects of critical heterogeneities on fluid production and trapping.

Industry has shown considerable interest in NIPER's reservoir characterization capabilities, many of which have been developed under the BE1 program. A multiclient project which investigated methods to quantify spatial variations in reservoir parameters has been conducted. Consultations to operators of barrier island reservoirs, as well as other reservoir types, using NIPER methodology developed under BE1 for seservoir characterization have been provided. Most of the field projects conducted with industry cosponsorship, such as the MEOR and subsurface production projects, involve considerable reservoir characterization in the early stages. At the two resenvir characterization technical conferences, cosponsored by NIPER and

DOE, most of the presentations were made by industry representatives. Companies which have interests in reservoirs investigated by NIPER have been cooperative in providing core, $\log _{\text {, and }}$ production data. In Patrick Draw field, which NIPER studied during FY90, thie operator is planning to implement EOR and could be amenable to a cooperative project to select and design an appropriate EOR method. Industry participation in NIPER's reservoir characterization research and development is expected to continue. 
Numerous publications and pre sentations have resulted from the work performed as part of project BE1 over the past several years. In addition, technology developer under DOE sponsorship has been used for individual inoustrial clients and in multiclient projects.

\section{OBJECTIVE}

The objective of this project is to develop a methodology for the effective characterization of shoreline barrier reservoirs. Shoreline barriars are ranked in the top 10 of priority reservoir geologic classes in the DOE Oll Research Program Implementation Plan. Such a methodology is necessary to predict residual oll saturation distribution and reservoir performance during various recovery processes.

\section{SCOPE OF WORK}

This project will develop an improved methodology for effective characterization of shoreline barrisur reservoirs to predict residual oil saturation (ROS) at intewell scales in shoreline barrier reservoirs and improve predictions of flow patterns of injected and produced fluids, given the location of injection and production history. Reservoirs for characterization will include a variety of shoreline barriers (spits, shoals, barrier islands, barrier peninsulas, and barrier bars). These formations will be classified according to their relative growth (aggradational, progradational, transgressive). The degree of tide or wave domination and the influence of tidal range (microtidal, mesotidal) will also be used to classify internal reservoir geometry (heterogeneities) and their relative iniluenie on recovery. This project is multiyear, and it is probable that the tasks listed will not be completed during FY91. Technology transfer of the results of this project will be accomplished through the preparation of journal anticles subject to peer review and presentations for symposia in addition to the topical report described in the Deliverables section of this plan.

Iask 1. Construct quantitatlve geologlcal sherellne barrler model for Patrlck Draw field. (Start date: October 1990. Completion date: September 1991.) (Near- io mid-term)

Patrick Draw field, a mesotidal, giant barrier island reservoir in the Rocky Mountains, will be used for generalization of the shoreline barrier model. Depositional, structural, diagenetic, and geochemical partial models will be constructed and integrated io form a comprehensive, quantitative geological model. Available information from outcrop studies will also be integrated into the comprehensive geological inodel for interwell scale information.

Because implementation of the task is interdisciplinary, it will provide both near- and intermediate-term results relative to: (1) integrative methodology for enhanced resource utilization from shoreline barrier reservoirs; (2) optimization of data gathering and most effective 
data utilization; (3) prediction of location and distribution of residual oil saturation within specific shoreline barrier reservoirs; and (4) technology transfer of the most effective techniques for characterizing shoreline bariler reservoirs.

Iask 2. Construct enalneerlng model of Patrlck Draw fleld. (Start date: October 1990. Completion date: September 1991.) (Near- to mid-term)

Accurate reservoir description is a main prerequisite for successful planning and implementation of EOR and infill well drilling programs. This task develops an effective and efficient reservoir description method by using only readily available wireline logs and well production, injection, and pressure data. Conventional techniques such as volumetric calculations, material balance, decline curve, production-injection, and well test analyses will be used to diagnose reservoir heterogeneities. The engineering model will be integrated with the comprehensive geological model to provide an integrated engineering-geological model of Patrick Draw fleld. The engineering model will provide an independent source of information for reservoir description.

Iask 3. Geostatlstlcal analysis of Patrlck_Draw fleid. (Stant date: October 1990. Completion date: September 1991.) (Near-term)

Geostatistical techniques such as kriging and fractal analysis will be used to estimate interwell reservoir properties in Patrick Draw field. The application of geostatistics to the barrier island reservoir (specifically Patrick Draw field) may reveal additional information to aid in understanding this type of formation. The comprehensive production information will also provide a good opportunity to investigate strengths and weaknesses of different geostatistical techniques. Study of fractal distributions of important formation parameters such as porosity, permeability, saturation, and pay thickness can be used to revise or supplement the geological model of banier isiands.

Task 4. Develorment of Improved methedoloav for characterialng shoreUne barrler reservolrs. (Start date: Ostober 1990. Completion date: September 1991.) (Mid-term)

The meihodology developed during the first phase of reservoir characterization of shoreline barrier reservoirs (Bell Creek study) will be expanded with emphasis on mesotidal barrier island deposystems. This methodology will provide guidelines about data-gathering, sequence, quality, and quantity of data required for characterizing shoreline barrier reservoirs. The methodology also addresses possible recovery methods that may be applied for efficient explottation of mesotidal barrier type of reservoirs. As part of this task, the similarities and 
differences among the various shoreline barrier systems will be examined in light of expected production behavior for the respective systems.

Iask 5. Development of a data base tor shorellne barrier formatlons. (Start date: October 1990. Completion date: September 1991.) (Near-term)

The objective of this task is to organize all geological and engineering information available about the shoreline barrier systems investigated as a part of this project. This data base will provide the capability to perform quantitative and integrative analysis as well as assist in the construction of crossplots and maps. This data base will provide guidelines for the identification of expected heterogeneities in shoreline barrier systems to major and independent oil companies in addition to the DOE. The preliminary data base will be developed using data from Patrick Draw field.

\section{DELIVERABLES}

Sep 91 Topical Report - fo include (1) a discussion of the most effective techniques for characterizing shoreline barrier reservoirs, including similarities and differences among the various shoreline barrier systems; (2) a description of the integrated engineering-geological model of Patrick Draw field; and (3) a description of the shoreline barrier data base.

\section{PLANNED STAFFING}

$\begin{array}{lc}\text { Senior and Research Engineers } & 1.3 \\ \text { Senior and Research Geoscientists } & 2.8 \\ \text { Technicians } & 1.7 \\ \text { Total } & 5.8\end{array}$

\section{Project Leader}

Matt Honarpour, Senior Engineer

\section{EQUIPMENT REQUIREMENTS}

Avallable Now

Core saw

Core Polisher

Apparatus for UV and Visible Photography of Cores 


\section{BE2. - TORIS RESEARCH SUPPORT}

\section{BACKGROUND}

This project provides research support for the Tertiary Oll Recovery Information System (TORIS) in the areas of EOR project and reservoir data base management; EOR project technology and trends analysis; and evaluation of computer models and numerical simulators. It is necessary for TORIS to have accurate information on EOR projects and reservoirs that can be retrieved quickly. It is also necessary to have rellable computer models and numerical simulators. NIPER maintains EOR project and reservoir data bases with currently available information and efficient retrieval. NIPER analyzes data trends in EOR and computer models and numerical simulators as they relate to needs of TORIS. This work has resulted in annual reports on the trends in applying EOR technology. Analyses of simulators have resulted in subsequent improvements in the simulators before they were accepted by DOE for distribution.

Information that is incorporated litto the TORIS project database is provided by oil companies. These companies participate in DOE ECR incentives projects and provide information on production and other activities. Upon approval by the DOE Program Manager, the system is used to provide statistical analysis of information on reservoirs and EOR projects to industrial clients, which include independent oil companies and service companies. Information is also provided to other DOE-sponsored research projects.

\section{OBJECTIVES}

To provide research support for the Tertiary Oll Recovery Information System (TORIS) in the areas of EOR project and reservoir data base management, EOR project technology and trends analysis, and evaluation of computer models and numerical simulators.

\section{SCOPE OF WORK}

Iask 1. EOR prolect data base research_support. (Start date: October 1990. Completion date: September 1991.) (Near-term)

Areas of work in FY91 are as follows:

A. Maintain the EIA and RELIANCE versions of the EOR project data bases and associated routines to be current with active versions of S2k, RELIANCE, communications, and operating systems. Maintain and update data as necessary for input from BPO.

B. Transfer 1989 (if available) production data for DOE cost-shared and incentive projects into the EOR project data bases. Sollcit completed FE-748 forms for the active EOR incentive projects for 1990. Deliver to BPO a security copy of the EIA S2K version of the data base and a status report on data additions and solicitation results. 
C. Review literature for new data on existing and new EOA projects. Install collected data on EOR project data bases. Analyze trends in the application of EOR technology and prepare a topical report presenting this analysis.

D. Assist BPO in publishing an updated description of the EOR project data bases.

Iask 2. Reservoir data base research suppont. (Start date: October 1990. Completion date: September 1991.) (Near-term)

Areas of work in FY91 are as follows:

A. Maintain the EIA RSVR data base and routines to be current with new versions of S2k, communication, and operating systems.

3. Continue the development of a reservoir data base management system started in FY90 as part of Project SGP28, "Development of Reservoir Data Base - Phase 1." Work will progress to the point of an operating DBMS. Refinements and a user's manual will be written in FY92.

C. Add and modify resenoir data as required.

Iasks 3. Computer modelling research suppon. (Stan date: October 1990. Completion date: September 1991.) (Near-term)

Areas of work in FY91 are as follows:

A. Evaluate simulators and computer models as required for the TORIS program. Assist BPO in answering inquiries concerning publicly available simulators.

\section{DELIVERABLES}

Sep 91 Topical Report on EOR Trends

Sep 91 Status Report on Addtions to the Data Bases

\section{PLANNED STAFFING}

\section{Man-Yoars}

Data Analysts

1.6

Engineers

0.2

Geoscientists

0.8

Technicians

0.5

Total

3.1

\section{Project Leader}

James F. Pautz, Research Data Analyst 


\section{EQUIPMENT REQUIREMENTS}

\section{Avallable New}

Personal Computer 


\section{BE3. DEVELOPMENT OF IMPROVED MICROBIAL FLOODING METHODS}

\section{BACKGROUND}

Due to increased use of processes based on biotechnology, renewed interest has been given to the use of microorganisms for enhanced oil recovery (EOR). Several major oil companies are currently conducting fleld pllots, or laboratory research leading to field pilots. A Fossil Energy staff study, "The EOR Initiative", has stressed the need for shorter term oll recovery activities for independent petroleum producers, declining oll flelds and stripper wells. These activities are particularly important because "independent operators produce about $40 \%$ of the total oil recovered, but cannot conduct needed EOR research." Microbial methods for improving oil recovery epe potentially cost-effective, and particularly well suited to be appiled in today's economic climate. The technology is flexible, currently available, relatively inexpensive, and can be applied by independent producers to extend well life in the near-term. Microbial formulations can be applied in a variety of methods including well simulation treatments, permeability modification treatments, and microbial-enhanced waterflooding. Well stimulation treatments are relatively inexpensive, easy to implement, and can provide rapid recovery of the minimal investment costs. Microbial-enhanced waterflooding is a method that has significant potential for increasing producing from aging oil fields that are currently under waterllood. The incremental cost for injecting microbos and nutrient is relatively small in an existing waterflooding operation, which may make this method applicable at low oll prices when more expensive methods are not economically feasible.

Application of this novel EOR technology to increase oil production requires careful laboratory design of the microbial formulation to optimize its performance for the particular application, reservoir characterization to define the important geological parameters, and reservoir engineering design to ensure that the method is applied in an efficient and cost-effective manner. As an example, a microbial yormulation that is effective in modifying permeability and increasing sweep efficiency is not necessarily effective in emulsifying paraffin deposits or increasing microscopic oil displacement efficiency.

To date this project has achieved both long-term and near-term goals, including the improved understanding of the mechanisms of oil mobilization by microbial formulations and transport of microbes and their metabolites in porous media. The concepts and data from this research project formed the basis of applied research needed to develop engineering methodologies for field applications.

A key result from NIPER's BE? applied research program is the development of a microbial culture bank consisting of different types of microorganisms that can improve oil mobilization under a wide variety of conditions. NIPER is currently applying MEOR processes to a reservoir 
that is a member of one of the higher priority reservoir classes (Fluvial-dominated deltaic) based upon geologic history outlined in the Oll Research Program Implementation Plan. A microblalenhanced waterllooding fieid pllot project was initlated in Delaware-Childers fleld near Nowata, Oklahoma, to address the near-term needs of independent producers to apply this technology. The project was intiated in a mature waterfiood with producing oil wells that are in the stripper category. The resenvolr is typical of a mid-continent sandstone reservolr. The results of the field pllot test are addressed under project SGP-13. Both this base program project (BE3) and the near-term fleld pllot test (SGP-13) have been in progress concurrently for the past several years. They are both part of NIPER's integrated program to develop and apply MEOR technology to increase our nation's reserves of crude oll.

Because of the potential opportunities for independent oil producers to use a costeffective enhanced oil recovery (EOR) technology, NIPER has prepareri and given short courses for independent petroleum producers on microbial EOR. Approximately 450 independent oil producers, major oil company representatives, and interested participants from other nations have attended these short courses. A major goal of these short courses is to demonstrate the potential for microbial technology to assist in improving oil recovery from marginal oil wells. Today in the United States $73 \%$ of all producing oil wells are producing less than 10 barrels per day and are classified as stripper wells. Stripper wells are responsible for $15 \%$ of domestic oil production, but produce an average of less than 3 barrels per day. The short courses emphasize the potential for MEOR, yet stress the need for applying the technology properly through careful engineering design for maximum economic return and oil recovery.

One of the major constraints to MEOR technology has been the lack of simulation data to adequately describe and predict the MEOR processes both in the laboratory and in the fleld. During the 1980's, Feiearchers at the University of Oklahoma, and Southem California University studied transport of several different types of bacteria to produce one-dimensional models. It became apparent that microbial transport in porous medla was an extremely complex phenomenon that required further laboratory and field data to adequately model. While several attempts have been made to modity existing reservoir simulators to describe microbial processes, no model has yet fully incorporated all of the complex phenomena that are believed to be, important. Thus, an accurate reservoir simulator for MEOR methods can best be developed through an integrated program of acquistion of laboratory and field data with the feedback loop being the reservoir simulation model. The uniqueness of this project is the integration of laboratory and field data in a numerical simulator to adequately describe the recovery mechanisms and microbial transport processes. Technology transfer will be accomplished through dissemination of field and laboratory information to independent operators through personal 
contacts, tour of MEOR field sitt and publicatior, of refereed technical journal articles and presentations at symposia

The unusual complexity of oil recovery by microbial formulations will obviously require close coordination between laboratory mechanistic studies and oil displacement experiments under carefully controlled conditions to develop and validate a computer model.

NIPER has amassed a wealth of laboratory and field data on the mechanisms of oil mobilization of microbial formulations and the effects of various design parameters on oil recovery efficiency. Research using laboratory experiments in FY90 began to define key mechanisms of oil mobilization. Work for FY91 will continue to develop the critical parameters, correlations and mathematical models to describe the physical phenornena that are important in MEOR methods, and development of a mathematical computer simulator to model and predict performance of microbial formulations in oil recovery applications.

\section{OBJECTIVE}

The objective is to develop microbial technology for enhanced oil recovery field applications using an integrated laboratory and field effort to define the critical parameters required for modeling MEOR processes.

\section{SCOPE OF WORK}

Laboratory data from NIPER will be used to develop correlations and mathematical models for specific phenomena and linear coreflooding data will be used to test the simulator in an iterative process. The simulator development and laboratory testing aspects of this project will be carefully coordinated so that the results from testing the simulator with oil displacement experiments will be used to design laboratory experiments to clarify and quantify certain physical effects from which correlations will be refined and modified that will be incorporated into the simulator. The numerical simulator will be the primary deliverable from this research, and studies for its development and use will probably result in several journal articles that will be subject to peer review. The overall goal of the project is to develop a method for predicting and evaluating microbial EOR processes in porsus media.

Iask 1. Revlew all laboratory data and modify (li necessary) the plan develoned in FY9o for laboratory evaluatlons of MEOR processes. (Start date: October 1990. Completion date: November 1990.)

Laboratory simulation of MEOR processes will continuously be modified in accordance with specifications in the plan. The data obtained from displacement studies will be incorporated into the model, and then used to define further displacement experiments. Based upon last year's results, further definitions of the parameters that are required to predict the behavior of 
microorganisms will be made. Preliminary data from last year's experiments indicated that microbial oil mobilization in porous media probably occurs by a combination of chemicals produced by the microorganisms in situ at the oil/water interface. These chemicals can alter wettability of water-wet rock, and reduce interfacial tension at the oil/water interface. More experimients are required to validate this hypothesis.

Iask 2, Develop mathematlcal descrlotlons for oll mebllizatlon by micro: erganlsms. (Start date: October 1990. Completion date: December 1990.)

Data obtained from experiments dealing with the interfacial phenomena associated with microbial oil mobilization will be used to develop mathematical descriptions that describe the process. Because $c$ the conplexity of these phenomena, there are no existing mathematical equations that adequately describe microbial oil mobilization in porous media. Probably the most critical question to be answered in the development of these equations is, does one incorporate all of the microbial products responsible for oil mobilization, or which ones are important?

Iask 2. Correlate laberatory displacement tests with mathematleal des:criptlens. (T) ant date: January 1991. Completion date: August 1991.)

Based on the mathematical descriptions, laboratory displacement tests in porous media will be conducted to fit the mathematical model. By continually adapting the model to fit laboratory data, we can make an accurate assessment of microblal oil recovery technology, predict the behavicir of the process, and have the ability to make modifications of the process.

'Lask 4. Using laberatery dlsplacement tests, compare mechanlsms of oll mobjlization by selected microblal specles currently used in permeabllity modl: ficatlon field lests with these microblal specles used in microsceple oll displacement. (Start date: October 1990. Completion date: August 1991.)

The experiments designed for microbial oil displacement studies will be used to evaluate those microerganisms that are being developed for permeability modification. The mechanisms of oil mobilization by these microorganisms are entirely distinct from the microorganisms that mobilize oil by surfactant, gas, acid and alcohol production. The same types of experiments describing the interfacial phenomena between microorganisms and oil will be designed for microorganisms that produce polymer and biomass.

Iask 5. Develob mathemailcal dessubtlons for oll mobllyation by microorganlsm, used in permeability modificalion tests. (Start date: June 1991. Completion date: Septernber 1991.) 
Based upon the above experiments, a set of mathematical equations will be developed for predicting how the oil mobilization process is affected by polymer-producing microorganisms.

Iosk_6. Fine-tune computer model for laboratory corefloods. (Start date: May 1991. Completion date: September 1991.)

The mathematical equations will be used to fit laboratory coreflood data in order to predict oil recovery with the microbial process.

\section{DELIVERABLES}

May 91 Status report on development of mathematical descriptions to represent microbial oil mobilization phenomena

Aug 91 Topical report on development of computer model for microbial oil displacement.

\section{PLANNED STAFFING}

Senior Biologist

Sr. Reservoir Engineer

Associate Blologist

Sr. Bioexperimentalist

Sr. Technician

Total
Man-Years

0.7

0.2

0.7

0.6

0.7.

2.9

\section{Prolect Leader}

Dr. Rebecca Smith-Bryant, Sr. Biologist

\section{EQUIPMENT REQUIREMENTS}

Laboratory coreflood apparatus

Avallable New

Gas chromatograph

3

Video-enhanced microscope

1

Phase contrast microscope

Coreflooding apparatus with intermittent pressure transducers

Anaerobic glove box

Capital Equipment Required: 


\section{BE4A. - DEVELOPMENT OF IMPROVED SURFACTANT FLOODING METHODS}

\section{BACKGROUND}

Chemical flooding has the potential of mobilizing more residual crude oll than any other method of enhanced oil recovery. In addition, for many shallow U.S. domestic reservoirs in which steam and gas flooding are not applicable, chemical flooding may be the only viable EOR method. Chemical flooding is technically very flexible because of the ability to vary an injected chemical formulation to provide oil recovery capability for a number of different reservoir conditions. However, from the point of view of economics, surfactant/polymer flooding is an EOR process that will need mid- to long-term research and development to overcome problems associated with successful application of the technology. Problem areas that need to be addressed include chromatographic separation of components from the chemical formulation, surfactant adsorption, precipitation, phase trapping, incompatibility with reservoir brines, and economics.

The application of improved chemical flooding methods will be directed towards a priority class of reservoirs: Emphasis will be made on well established chemical flooding EOR screening criteria to match the guidelines stipulated in the Federal Oil Research Program Implementation Plan. Information obtained from the National Reservoir Data Base and the DOE Bartlesville Project Office Ciude Oil Analysis Data Bank has been used to identify the range of conditions of temperature, salinities, and API gravities of reservoirs that can be considered as potential candidates for surfactant-based EOR methiods. About $60 \%$ of the reservoir conditions fall within a fairly broad range of temperature $\left(<180^{\circ} \mathrm{F}\right.$ ) and salinity (<10.3\% TDS). The remaining $40 \%$ of these reservoirs have harsher conditions.

The goal of the NIPER research is based on the need to improve the application of surfactant flooding methods of producing oil over a fairly broad range of conditions that otherwise would not be recoverable by other technically proven or more economical methods. The results from this on-going research is conveyed to the petroleum industry through NIPER and DOE reports, SPE papers, and teshnical articles in the open literature.

The first area of research will provide basic knowledge to develop the methodology of using mixed surfactant systems for cost-effective chemical flooding. Mixed surfactant systems offer a mechanism to provide a surfactant system with adequate interfacial tension (IFT) reduction and relatively high oil recovery potential coupled with improved temperature, salinity, and hardness tolerance. Variation in the relative composition of the mixed surfactant system can be used to fine-tune and broaden the conditions of optimum behavior to those existing in a specific reservoir. Thie existence of a positive synergistic effect can be exploited in such a way that the overall surfactant system will retain relatively low IFT values over a fairly broad range of reservoir 
conditions. This project provides mid- to long-term research efforts which can support near-term application of surfactant flooding methods in appropriately chosen reservoirs.

Studies of mixed surfactant systems were initiated in FY90. These studies included alkylaryl sulfonates with carboxyethoxylated surfactants or alpha olefin sulfonates and observed low IFT values for salinities up to $10 \%$. For FY91, NIPER proposes to build on this base of information. Stucites will include phase behavior, solution calorimetry, surfactant loss, and oll recovery efficiency of selected surfactant systems. Methods to correlate structure-property relationships will continue to be evaluated to facilitate the rapid selection of surfactant systems for specific reservoir conditions. In addition, development of the technology for successful application of surfactant flooding will include evaluation of methods to reduce surfactant loss and to improve surfactant propagation through the reservoir, with the objective of reducing the cost of surfactant flooding.

The successful application of surfactant systems over broad conditions of salinity and temperature requires an understanding of how these surfactants behave under such conditions. NIPER's calorimetric capability will be usei to correlate the solution behavior of surfactant systems with their performance. Such correlations were begun in FY89 and continued in FY90. Recovery of petroleum irom a reservoir using chemical flooding involves reducing drive fluid-oil IFT. The most effective reduction in IFT usually occurs at or above the critical micelle concentration (CMC) of the aqueous surfactant solution. The CMC of surfactant systems increases with temperature and decreases with electrolyte concentration. If the $\mathrm{CMC}$ of the drive fluid is unknown at reservoir temperature and salinity, then the most economic concentration of surfactant is unknown. Hightemperature calorimetry will be applied to some of the more promising surfactant systems selected above to provide auxiliary information on their CMC's and solution propertles.

The second area addressed by this research piogram is to improve the economics of surfactant enhanced oll recovery processes. One promising technology for light oll recovery application Includes the addition of alkaline additives to reduce surfactant loss, enhance interfacial tension reduction, and allow the use of lower concentration of expensive surfactant chemicals. Research on the use of alkaline agents as additives to surfactant formulations has evolved over the past few years as a possible low-cost surfactant-based EOR method. This work was first conducted using acidic oils. It was believed that the primary effect of the alkali was neutralization of carboxylic acids present in acidic crude oils. However, it has been shown recently that a synergism exists between surfactants and alkaline additives, even when the oils have very low acid numbers. This leads to the possibility of a more near-term application of this technoiogy to a larger number of reservoirs, including many midcontinent reservoirs that contain slightly acidic, light crude oils. In the presence of alkaline additives, very dilute $(0.1-0.2 \%)$ concentrations of synthetic surfactants are sufficient to mobilize significant amounts of residual oil. Since synthetic 
surfactants are expensive components, this can lead to more favorable economics in surfactant flooding field projects.

For FY90, research was conducted with two midcontinent crude olls: one from Teapot Dome (WY) fleld and the other from Delaware-Childers (OK) field. For FY91, these experiments will be extended to include several reservoirs that meet the selection criteria set forth in the Federal Oll Research Program Implementation Plan. The research will be conducted using oil, brine, and cores from the selected fields. If the results of laboratory tests are favorable, and the economics of oll recovery appears to be favorable, rocommendations will be made for a near-term application of this technology in a midcontinent reservoir under the Supplemental Government Program (SGP).

The third area of research for this program provides near-term adaptation of chemical flooding technology to the solution of near-wellbore injectivity problems. The application of chemical flooding technology is not limited to conventional micellar-polymer flooding. The current avallable chemical flooding technology can be further extended for application in well stimulation and cleanup to extend the life of low-cost secondary recovery mechanisms. Problems relating to loss of fluid injectivity and paraffin deposition and plugging represent major concerns for small independent and major oil producers who may be helped by methods using currently established chemical flooding technology. Chemical flooding based methods represent a viable alternative to conventional thermal-based treatments.

Loss of drive-fluid injectivity can result from a variety of factors, particularly those related to completion and treatment methods. In some cases, formation damage is a direct result of the presence of residual oil in formation pore spaces in the near-wellbore region. The application of surfactant-based methods will help remove or sweep the residual oil saturation from this region and thereby improve overall injectivity. The increase in injectivity does not directly correspond to an increase in amount of oil recovered but rather relates to an accelerated rate of recovery of oil, thereby improving the economics of conventional waterflood processes.

The precipitation and deposition of paraffin particles has been a recurring problem related to crude oil production. The relatively high cost of conventional ireatment methods can lead to abandonment of marginal stripper wells. The deposition of these solid or waxy materials frequently occurs in well bores and on tubing strings. The mechanism of deposition is brought about when the oil is cooled below the cloud point of the crude oil componsnts. The common methods for dealing with this buildup are mechanical, thermal, and chemical. The chemical based treatments used are predominantly either dispersant mixtures or a variety of solvents having high aromatic content. Some of these conventional methods, such as hot oll treatments, have been demonstrated to cause further paraffin precipitation and formation damage. Surfactant-based methods can provide a better alternative for the control of paraffin deposition and removal of 
these deposits. Methods Involving surtc ctants used in combination with conventional methods such as "hot surfactant" or "hot oil" treatment can be developed to Improve the efficlenoy of the overall treatment process.

A task has been outllned for FYgr to evaluate the extension of current chemical flooding technology to alleviate low near-well bore injectivity and deposition problems and to conduct chemical flood research to reduce the cost of well stimulation. Successful implementation of this technology extension will translate into possible near-term fleld application of the developed chemical-based methods. Technology transfer of the results of this project will be accomplished through the preparation of peer-reviewed journal articles and presentations for symposia in addition to the topical and status reports described in the Deliverables section of this plan.

\section{OBJECTIVES}

To improve chemical flooding technology through the development of mixed-surfactant systems which are more tolerant to changes in chemical composition in the reservoir. The focus will be to mitigate problems which have been shown to have adverse effects on the performance and economics of surfactant flooding processes. To improve the economics of surfactant enhanced oil recovery through the development of effective oll recovery systems that contain very low concentrations of synthetic surfactants and alkaline additives. To investigate the application or extension of current chemical flooding technology to near-term problem solving for near wellbore paraffin removal and waterflood injectivity improvement.

\section{SCOPE OF WORK}

Iask 1. Evaluatlon of mlxed surtactant systems for chemleal flooding an-

pllcation. (Start date: October 1990. Completion date. September 1991,j (Mid-term)

Evaluate mixed surfactant systems that may have potential application for well-to-well chemical flooding, single-well chemical flooding, and near-wellbore remediation treatments (wettability change and injectivity improvement). These studies include phase behavior, IFT, adsorption measurernents, and determination of CMC's and solution behavior. Properties will be correlated with structure differences if possible. Oil recovery efficiencles will be determined from laboratory coreflood experiments, and deficiencies of surfactant recovery from produced fluids will be evaluated. A laboratory evaluation of single-well chemical flooding methods will also be conducted in anticipation of selection of field application. A candidate surfactant systern will be selected for a target reservoir. 
Iask 2. Laboratory ovaluatlon of surfactant flooding with alkallne additlvea for selected raservolr rocks and flulds. (Start date: October 1990. Completion date : September 1991.) (Near-term)

Select four light oll reservoirs from the mid-continent region that meet the selection criteria set forth in the Federal Oil Research Program Implementation Plan. Obtain oll, brine, and core samples from at least two of these reservoirs for laboratory evaluation of surfactant flooding with alkaline additives in the selected flelds. Interfacial tension tests and alkall consumption measurements will be used to design a surfactant system with alkaline additives that can be applied in the selected reservoirs.

Iask 3. Investlaatlon of applltatlon af surtactanteenhance ol oll recovery technlaues for near-wellbore permeabllity Imprevement. (Start date: October 1990. Completion date: August 1991.) (Near-term)

Evaluate available information on the causes of loss of permeability in the near-wellbore region. Determine which types of permeability impairment are amenable to rernediation by chemical methods, in particular, surfactant systems that will mobilize oll or components of the oll that block flow channels or change wettability to improve relative permeability to the component of interest. Wettability and oil/water relative permeability measurements will be conducted before and after treatment with selected surfactani systerns to determine effectiveness of the treatments for improving injectivily or oil-production in the near-wellbore region during secondary waterflood operations. Selection of targeted reservoir core and operating conditions will be based on anticipated selection of fleld application and technology transfer to independent operators in the near-term time frame. Evaluate and compare efficiency and economics of the surfactant remediation technique with that of other remediation techniques such as hot oll treatments and solvent extraction. The uttimate goal will be to prepare guidelines to ald oll producers in selection of approprlate treatments to extend the lite and efflcienoy of the more economical secondary oll recovery operatlons.

\section{DELIVERABLES}

Sep 91 Toplcal report on applications of Improved surfactant flooding methods

Sep 91 Topical report on appllcations of surfactant flooding with alkallne addlitives

Aug 91 Status report on application of surtactant flooding technology for near-wellbore permeability improvement 
PLANNED STAFFING

Man-Years

Senior Chemists

1.80

Senlor Engineer

0.80

Senior Experimentalist

0.60

Techniclans

1.60

Total

4.80

\section{Project Leader}

Leo A. Nill, Senior Chemist

\section{EQUIPMENT REQUIREMENTS}

Coreflood apparatus

High-temperature mixing calorimeter

Avallable New

Sorption calorimeter

1

Spinning drop interfaclal tensiometer

1

Titration calorimeter.

2

Conductance apparatus

1

Ion conductivity detector

1

CT scanner 


\section{BE4B. - DEVELOPMENT OF IMPROVED ALKALINE FLOODING METHODS}

\section{BACKGROUND}

The emerging technology in alkalline flooding of heavy oll is the use of a combination of surfactant and alkall. This has the potential for alleviating some of the problems associated with the use of either surfactant alone or alkall alone. In favorable cases, chemical requirements are reduced, displacement efficlency is improved, and scale formation is suppressed. Several mechanisms are involved that are partly understood and consist of both equilibrium and dynamic effects. The former includes interfacial activity, adsorption, and ionic equilibria (precipitation and complex formation) and are addressed by the design of the injected formulation. The latter includes chromatcgraphic effects, flow diversion by precipitates, and emulsification, and are addressed by injection strategy.

Several injection strategies have been used or suggested. Some examples are (1) the combination of alkali, surfactant, and polymer into a single slug followed by more polymer, (2) the combination of alkali and surfactant into a single slug, followed by polymer, (3) pre-injection of alkall to condition the reservoir, (4) surfactant followed by alkaline polymer, (5) injection of oil soluble acids followed by alkall, and (6) various injection strategies that utllize surfactant concentration gradients.

Proper design of injection strategy can be viewed as a near-term project as well as long-term research. In the near term, this research will support the design of the proposed surtactantenhanced alkaline flooding fleld pllot test which will be conducted under the SGP. After the identfication and selection of a project site and establishment of a joint venture between the participants, oil and cores from the site can be used for the optimization studies. In the long term, the results of injection strategy research will provide a base of information for future field tests.

\section{OBJECTIVES}

To develop improved alkall-surfactant flooding systems and to provide support for an SGP fleld project.

\section{SCOPE OF WORK}

Injection strategy is an aspect of optimization that needs to be addressed by coreflood and slim tube sandpack tests. The tests that are performed will be selected from the following tasks. To isolate effects, some tests are best performed in the presence of divalent ions and some in the absence of divalent lons. Crude oll from the site of the SGP field pilot will be used for some of the tests after that site is selected. If the crude oil from the SGP site is different from the olls previously tested, then interfacial tension and phase behavior tests will be required for the new oll. 
Iask 1. Injectlon strategles in the absence of divalent lons. (Start date: November 1990. Completion date: August 1990.) (Near-term)

Investigation of the best injection strategy is an aspect of optimization that needs to be addressed by corefloods. The effect of injection strategies on the interactions between the chemicals used for flooding and the oll are best studled in the absence of divalent ions. Several injection strategles will be studled and may include any of the following: (1) alkall and surfactant followed by polymer, (2) surfaciant followed by alkaline polymer, (3) oll soluble acids followed by alkaline polymer, and (4) surfactant concentration gradient iiljection.

Task 2. Iniection strategles deslaned to inltlaate the adverse effects $\Omega$ f divalent lons. (Start date: February 1991, Completion date: August 1991.) (Near-term)

The use of injection strategies designed to protect the injected chemicals from the adverse effects of divalent cations will be the focus of this task. The several injection strategies will include: (1) surfactant followed by alkaline polymer and (2) preinjection of alkali.

\title{
DELIVERABLE
}

Sep 91 Topical report comparing the various injection strategies, economics and suggestions on the best strategies for fleld use.

\section{PLANNED STAFFING}

Senior Chemist

Man-Years

Senior Experimentalist

0.6

Total

0.4

1.0

\section{Project Leader}

Troy R. French, Senior Chemist

\section{EQUIPMENT REQUIREMENTS}

\author{
Coreflooding cquipment \\ Spinning drop interfacial tensionmeter
}

$\begin{array}{cc}\text { Avallable } & \text { New. } \\ 1 & \\ 1 & 1\end{array}$




\section{BE4C. - DEVELOPMENT OF IMPROVED MOBILITY-CONTROL METHODS}

\section{BACKGROUND}

This proiect aims at developing two products that are essential to improved waterflooding and chemical flooding. Improved waterflooding through improving sweep efficiency, reservoir conformance, and profile modification is an economic process, currently being applied by operators, and is one of the processes proposed in the Oil Research Program Implementation Plan as having the potential, in the near-term, to arrest the rate of well abandonment. The first product is a mobile, and flexible low-molecular-weight polyacrylamide gel which can alleviate the problems or poor injectivity and mechanical degradation one encounters in the traditional hiahmolecular-weight polyacrylamide. The second product is a simulator for the design and prediction of the recovery efficiency of profile modification process using high-molecular-weight gels which has been studied by Wilhite and Green at the University of Kansas for more than a decade. NIPER's research program complements the efforts at the University of Kansas.

\section{Moblilty-Control Agents}

Dilute solutions of high-molecular-weight polyacrylamides and biopolymers have been used by many independent oil producers and major oil companies in oil fields as mobility control agents to improve sweep efficiency and to increase oil recovery. The drawback in using polyacrylamides are their susceptibility to mechanical degradation, which is irreversible and can reduce their effectiveness as mobility-control agents and cause losses in injectivity. One strategy for mitigating the effects of mechanical degradation is the use of low-molecular-weight polymers. However, use of low-molecular-weight polymers requires considerably greater polymer concentrations to achieve an increase in viscosity equivalent to that with a high molecular-weight polymer. One alternative is to use crosslinked low-molecular-weight polymer formulations which should not be as susceptible to mechanical degradation and could provide good injectivity under high shear conditions.

NIPER is the only laboratory undertaking this kind of study. Research at NIPER on the development of unique crosslinked reiative low-molecular-weight polymer gels for mobility control (rather than for profile modification) began in FY88. Screen tests have shown that crosslinked low-molecular-weight polyacrylamide gels for mobility control can be formulated with $\mathrm{Cr}(\mathrm{III})$ (pH = 4.8) and $\mathrm{Cr}(\mathrm{VI})$ /thiourea $(\mathrm{pH}=6.8)$ using low-molecular-weight polyacrylamides. Gels that can be formed at neutral pH have also been formulal $3 d$ with a low-molecular-weight polyacrylamide and an aluminum citrate crosslinker. (These formulations are less likely to present environmental problems than chromium salts). Screening tests conducted in FY88 on two partially hydrolyzed low-molecular-weight polyacrylamides also revealed that gelation conditions were affected by the degree of hydrolysis. The degree of hydrolysis has also been shown to attect the geiation raie oi 
a conventional polyacrylamide with a metal crosslinking agent. In FY90, screening tests were conducted to determine the effect of the degree of hydrolysis on gelation kinetics and gel strength. These studies will allow the selection of the optimal degree of hydrolysis for making cost-effective low-molecular-weight polymer gels for mobility control.

Shear experimerits in a pack of five randomly packed 100-mesh screens have shown that crosslinking bonds can be broken under a high shear condition and will reheal (reform) under a subsequent low shear condition. The ability of broken bonds to reform under low shear conditions will permit the healed gelled polymer to regain viscosity and to reduce water mobility as it flows through reservoirs. These results demonstrate that crosslinked low-molecular-weight gels not only can overcome the shear degradation problem but also can improve injectivity over that of conventional high-molecular-weight polyacrylamides. In FY91, shear experiments will be extended to porous media that have lower permeabilities. Results will be compared with those of a conventional polyacrylamide. If it can be shown that crosslinked low-molecular-weight poiymer gels are more effective in controlling mobility than conventional polyacrylamides, some gel systems will be formulated and optimized for selected reservoirs in a high-priority class. If field tests are successfu' technically and economically, this near-term technology will be transferred to independent oil producers to improve oil recovery.

\section{Permeablilty Modification}

Many high-viscosity polymer gel systems have been developed for profile modification. Some of them have been successfully applied to many oil fields by independent oil producers and major oil companies to improve volumetric sweep efficiency and increase oil production.

In planning the treatments for permeability modification, the producers usually have the problems of determining the best initiation time for a gel treatment and how far the gel should penetrate in high-permeability layers. Problems like these can easily be answered by using a simulator. Such a simulator must be able to describe the transport of the chemical species and gelation reaction kinetics of the gel system in stratified reservoirs. It must also be able to account for phenomena such as inaccessible pore volume to macromolecules, adsorption of chemical species on rock surfaces, and retention of polymer gels on the rock matrix. Studies of these phenomena have been conducted in many university and industry laboratories. In FY88, a unique simulator that includes the above features was developed at NIPER for the first time for reservoirs that contain gas as a component. This simulator is very useful for simulating and optimizing any combination of primary production, waterflooding, polymer flooding, and permeability modification. This simulator has been used to dritermine the best initiation time for a gel treatment in a waterlood in reservoirs of different degrees of crossflow. Results showed that the best initiation time for a gel treatment in the injection well was the time immediately after water 
breakthrough occurred, regardless of the degree of crossflow. In FY90, simulation runs were conducted to investigate the effect of layer permeability contrast on the best initiation time and the effect of the depth of gel peietration on oil recovery. Specific reservoir evaluation using this simulator should be very helpful for independent oil producers in assessing potential fields for polymer gel treatments. In FY91, the work will be extended to investigate the effect of a gel treatment on oil recovery in a conventional polymer flood.

Through various means of technology transfer including reports prepared as deliverables to the DOE, technical papers for presentations at society meetings, and refereed journal articles, the results of this project will be disseminated to the petroleum industry and others interested in this subject.

\section{OBJECTIVES}

To determine the ar.plicability of low-molecular-weight polymer gels for mobility-control applications and to investigate the effect of a gel treatment on oll recovery in a polymer flood.

\section{SCOPE OF WORK}

Comparison of the effect of shear degradation on the flow resistance of solutions of a few crosslinked low-molecular-weight gel systems and on that of a solution of a conventional polyacrylamide polymer will be made in low-permeability porous media to prove that crosslinked low-molecular-weight polymer gels are better mobility-control agents inan conventional polyacrylamide polymers. Flow resistance of selected gel systems will be measured at both high (typical of near-wellbore conditions) and low (typical of conditions far away from wellbores) flow rates. Results will be compared with that of a solution of conventional polyacrylamide (Pusher 500 in similar porous media under similar shear conditions).

NIPER's three-dimensional, three-phase simulator for permeability modification, developed in FY88, will be used to investigate the effect of a gel treatment on oil recovery in a conventional polymer flood. The merit of a gel treatment in a polymer flood will be assessed.

Iask 1 compare the effect of shear dearadation on the flow resistance of selected crossllnked low-molecular-weight gel systems and on that of a solution of Pusher 500 in porous medla. (Start date: October 1990. Completion date: August 1991) (Mid-term)

Flow resistance of selected crosslinked low-molecular-weight gel systems and that of a solution of Pusher 500 in porous media will be measured at both high and low flow rates typically encountered in reservoirs. The sequence of injection rates in each test will be (1) a low flow rate, (2) a high flow rate, and (3) a low flow rate. The effect of shear degradation on the flow resistance of all solutions before and after shear degradation occurs in porous media will be assessed. The 
effects of shear degradation on the flow resistance of crosslinked low-molecular-weight geiled polymers and on that of a solution of Pusher 500 will be compared.

Iask 2. conduct sensitivity runs using NIPER's simulator for affect of permeablility modiflcation on oll recovery in a conventlona _ polvmer flood. (Start date: January 1991. Completion date: June 1991.) (Mid-term)

To investigate the effect of a gel treatment on oil recovery in a polymer flood, sensitivity runs using NIPER's three-dimensional, three-phase simulator for permeability modification will be conducted using three-layer reservoir models (representative of Unit A, Bell sreek field sludied in BE1) of different degrees of crossflow.

\section{DELIVERABLES}

Sep 91 Topical report on the flow behavior of polymer gels for mobility control in porous media

Aus 91 Status report on the effect of gel treatment on oil recovery in a polymer flood

\section{PLANNED STAfFing}

Senior Chemist

Man-Years

Senior Engineers

0.05

Tochnician

1.00

Total

220

1.25

\section{Prolecel Leader}

Troy R. French, Senior Chemist

\section{EQUIPMENT REQUIREMENTS}

Contraves viscometer

Arellable New

Coreflood apparatus

9

Rotating reclprocating pump 


\section{BE5A. - GAS FLOODING}

\section{BACKGROUND}

Gas flooding is an effective method for enhanced oil recovery (EOR). Many large-scale $\mathrm{CO}_{2}$ and hydrocarbon floods are in progress in the United States. Nitrogen gas flooding processes also have great potential for enhancing recovery in condensate reservoirs and offshore reservoirs. According to the trend of recent EOR activities, gas flooding will become the most applied EOR method in the next decade. Widespread application of gas flooding is hindered by the poor mobility control and the uncertainty in predicting recovery efficiency in field projects. Although most research efforts are now concentrated on these problems, this project will focus on the effect of capillarity and porous medium on $\mathrm{CO}_{2}$-crude phase behavior, and on the development of techniques to improve the accuracy for predicting solid precipitation in $\mathrm{CO}_{2}$ flooding. Solid precipitation is a major near-term problem in $\mathrm{CO}_{2}$ field projects that causes formation damage and reduction in productivity. The ability to predict the conditions for solid precipitation to occur will allow engineers to design suitable methods to alleviate this precipitation problem.

In previous research at NIPER, systematic studies on nitrogen miscible displacement included phase behavior measurements and slim-tube and coreflooding tests. The displacement mechanisms have been investigated, and a minimum miscibility pressure (MMP) correlation has been developed. In the $\mathrm{CO}_{2}$ displacement studies, NIPER researchers have developed an accurate property prediction package for $\mathrm{CO}_{2}$ density and viscosity and physical property correlations for $\mathrm{CO}_{2}$-heavy oil mixtures. These results have been used by industry for gas EOR process design. The immediate application by industry of past results from laboratory research at NIPER demonstrates that short-term benefits often result from projects with long-term goals. In the past 2 years, research on gas mobility control and organic deposition occurring during gas miscible floods has been emphasized.

Phase behavior of injected gas with actual reservoir formation fluids may be different from that determined in a laboratory equilibrium cell. In an equllibrium cell, all fluids are well mixed and rapidly achieve equilibrlum; however, recent studles with molecular simulations have shown that fluld phase behavior inside micropores is quite different. The solld surface may Induce llquid condensation, and phase equilibrlum may not be achieved because of the restriction of a porous medium. Also, injected gas contacts only a small part of oll within a simulated time step. Therefore, the usual assumption of instantaneous equilibrium in reservolr simulations is unrealistic and may generate erroneous results. This phenomenon will be studied in FY91. 
A study of the problem of organic precipitation induced by gas flooding was initiated in FY 89. Deposition of asphaltic or paraffinic materials often occurs at or near wellbores and plugs or restricts flow producing wells. This deposition results in increased production costs and reduced productivity. In addition, deposition of these materials may alter rock wettability and relative permeability, thereby affecting fluid flow and recovery efficiency. In FY 91, the effect of asphaltene deposition on rock properties during gas flooding will be studied.

Parallel to the experimental studies, a more accurate prediction method for phase behavior will also be developed. The accuracy of phase behavior predictions using equations of state are still insufficient for systems such as $\mathrm{CO}_{2}-\mathrm{H}_{2} \mathrm{O}$-crude oils, and $\mathrm{CO}_{2}$-crude oils. Inaccuracy is even more serious in the supercritical region of $\mathrm{CO}_{2}$, which is extremely important to the $\mathrm{CO}_{2}$ miscible process. An improved equation of state is needed to accurately describe supercritical extraction and solid precipitation phenomena. An exising cubic equation of state (e.g RK-EOS) will be modified to improve its accuracy for predicting phase behavior, and to enhance its capability to be able to predict solid precipitation phenomenon.

The results of this project will be made available to the petroleum industry and the research community. In addition to reports to the DOE, refereed journal articles and presentations to professional societies will be prepared.

\section{OBJECTIVES}

The objectives of this project are to develop methods to mitigate the deleterious effects of solid precir wation in gas flooding, and to determine the effect of porous media on gas-oil phase behavior.

\section{SCOPE OF WORK}

The equations of state currently used in the petroleum industry will be modified to develop a technique for predicting solid (wax, asphaltene, etc.) precipitation and for predicting supercritical extraction with $\mathrm{CO}_{2}$-perfluorinated hydrocarbon fluids. Techniques to improve the accuracy in phase property predictions for $\mathrm{CO}_{2}$-crude oil systems will also be developed. PVT and coreflooding experiments will be conducted to determine the effect of porous media on gas-oil phase behavior, and recovery efficiency. Through coreflooding experiments, formation damage from asphaltene precipitation during gas flooding will also be studied.

Iask 1. Laboratory experiments to Investlogte the effecl of porous medla en Co2-oll phase behavlor. (Start date: October 1, 1990. Completion date: August 31, 1991) (Near-termi)

Perform phase equilibrium experiments using $\mathrm{CO}_{2}$-oil systems in an equilibrium PVT cell and compare the results with those in which the oil is stored inside a porous medium. Determine 
gas phase compositions as a function of time for both cases, and results from these two different experiments will show the effect of porous media on $\mathrm{CO}_{2}$-oil phase behavior. Conduct coreflooding experiments to study the effect of gas flow rate on phase equilibrium and displacement efficiency. Measure effluent compositions from these core flooding experiments to obtain information on the dynamic gas-oil phase behavior. This research will provide information for correlating the effect of porous media on phase behavior during simulation and will help to clarify the effects of this factor on solids precipitation being studied in task 3 . Because this is a scoping task, the level of effort for this task will depend upon the initial results.

Iask 2. Laboratory experiments to Investlgate the conditions for asphaltene preclpitation and its effect on formation damage. (Start date: November 1, 1990, completion date: September 30,1991) (Near-term)

Conduct $\mathrm{CO}_{2}$ coreflooding experiments to induce asphaltene precipitation. Measure the asphaltene contents of the crude oil before and after contacting $\mathrm{CO}_{2}$ to determine the quantity of precipitated asphaltene. Measure the permeability, and other physical properties of the cores before and after the coreflooding experiment to determine the degree of formation damage.

Iask 3 - Prodletion technique develooment for the description of solld precipltation. (Start date: October 1, 1990, completion date: September 30,1991) (Mid-term) Modify a cubic-iype equation of state (e.g. RK-EOS) to predict solid (wax, asphaltene, etc.) precipitation. The preliminary organic precipitation model developed during FY90 will be further refined and improved using experimental data from task 1 and task 2 of BE 5B.

DELIVERABLE

Sep 91 Topical report to describe all experimental results, the newly developed predictive technique, and computer codes.

\section{PLANNEd STAFFing}

Senior Engineer

Research Engineer

Assistant Engineer

Total

\section{Proipct deader}

Frank Chung, Senior Engineer

\section{Man-Years}

0.5

0.2

e.5

1.2 


\section{EQUIPMENT REQUIREMENTS}

\section{Avallable New}

Gas chromatograph

Phase equilibrium measurement apparatus

Coreflooding apparatus

1.

Data-acquisition system 


\section{BE5B. - MOBILITY CONTROL AND SWEEP IMPROVEMENT IN GAS FLOODING}

\section{BACKGROUND}

Gas flooding is an effective oll recovery process. Commercial scale carbon dioxide floods and hydrocarbon floods are in progress in the United States. Nitrogen gas flooding processes also have great potential for EOR applications in condensate reservoirs and offshore reservoirs. According to the trend of recent EOR activities, gas flooding, and in particular carbon dioxide flooding, could become the most popular EOR method in the next decade. The success of gas flooding in the United States is mainly attributed to the excellent displacement efficiencies usually obtained with miscible carbon dioxide flooding. However, low fluid densities and viscosities of the injected gases, as compared to common reservoir fluids, usually results in low sweep efficiencies. Consequently, extensive studies have been initiated to develop improved method of mobility control for miscible carbon dioxide displacement processes.

In previous research at NIPER, the use of foam for mobility control has been extensively studied and reported. Two papers describing research on foam conducted over the past 2 years.were accepted for the 1990 SPE/DOE Symposium on EOR. Variations of injection strategies have been shown to substantially alter the distance and effectiveness of foam flowing through slim tubes and linear corefloods. As a result of this work, additional questions, such as the following, were raised. Can these results be extrapolated geometrically to typical radial dimensions encountered near well-bores? Can foams be successfully generated and propagated by adjusting critical surfactant solution volumes, concentrations, and injection sequences for idealized radial flow, or must these parameters be further adjusted to account for discontinuous and heterogeneous fluid flow patterns?

The work proposed for this project in FY91 will include the expansion of capabilities at NIPER to evaluate foams under radial flow conditions. Preliminary research conducted during FY90 evaluated radial flow of foams using small cores. An initial assessment was needed to determine if differential pressure profiles and flow patterns could be altered and optimized by selecting appropriate injection strategies. Although the FY90 objectives were met, the small design of the radial core systern ( 6 in. diameter) could be used to study only areas near the wellbore $(<5 \mathrm{ft}$ ) and did not allow sufficient time for foam flow to attain steady state conditions. Consequently, an expanded radial flow physical model will be constructed and tested in FY91.

In addition to mobility-control studies with foam, evaluation of entrainers will continue into FY91. Entrainers are supercritical fluid additives capable of enhancing the phase behaviors or solvency properties of fluids. In other applications, entrainers have been able to increase the selectivity in supercritical extraction processes. For gas miscible flooding, these materials have the potential to improve displacement efficiency by increasing the solubility of marginally soluble 
components in crude olls; these materials also have the potential to improve mobility control from the viscosity contributions of the entrainer and additional hydrocarbon components solubillzed by the entrainer. Studies conducted in FY89 and FY90 have shown that certain materlals demonstrate some of the beneficial propertles necessary for enhanced mobility control. Current practices in the field have shown that for any method that can enhance gas mobility, immediate economic benefits are obtained by reducing the costs of re-injecting produced gas, and longterm economic benefits are obtained by increasing the total amount of oll produced for the gas injected. Research studies proposed for FY91 are to investigate some of the questions that remain to be answered before the technology can be applied in the fleld. The most immediate application under investigation (and the one getting the most attention) is with cyclic $\mathrm{CO}_{2}$ processes. Although mobility control may be less critical in cyclic processes, displacement efficlency is more critical. The additional crude oil components extracted by $\mathrm{CO}_{2}$ with added entrainer may reduce the soak time and improve the recovery efficiency of the cyclic $\mathrm{CO}_{2}$ processes. Such benefits would make the process more economically attractive to independent producers, particularly since cyclic $\mathrm{CO}_{2}$ processes would not incur high front-end costs. Furthermore, cyclic $\mathrm{CO}_{2}$ processes can be adjusted to fit the size of the operation, making this method very attractive to small operators. In contrast, traditional gas injection projects are often quite expensive and restricted to the larger operators having sufficient capital to cover the frontend costs. If the entrainer process shows promise in the studies conducted in FY92, a recommendation will be made to fleld test this technology with an operator, as a means of technology transfer.

In addition to evaluating entrainers for cyclic $\mathrm{CC}_{2}$ processes, additional evaluations will be made to further improve the entrainer technology. In FY90, some feasiblity studies suggested that in addition to alcohols and branched alkanes (1.e., 2-ethyl hexanol and isooctane evaluated in FY89 and FY90), other classes of compounds may be even more sulted as an entrainer for typical crude olls encountered in the fleld. Tasks proposed in FY91 will evaluate some selected compounds from these other compound classes. Included among these compound classes are perfluorinated alkanes. Although very little information is avallable on these compounds, what has been published indicates that certain compounds impart unusual properties to supercritical $\mathrm{CO}_{2}$ which results in substantially increased viscosities. Because of the inability of most compounds already tested to match these properties, it was proposed to include them in the entrainer evaluation. Environmental hazards by these compounds are expected to be minimal. Toxicity studies have indicated no adverse affects to animals, and these compounds would not be expected to endanger the upper atmosphere due to their absence of chlorine and their low volatilities. 
The last phase of entrainer evaluation includes a study of the performance sensitlvity to various injection conditions. The effect of conoentration, WAG cycles, and multiple entrainer injection cycles will be considered. The evaluation of these factors will provide a basis for making economic projections of this technique in a fleld environment.

Another unique approach to improving sweep efficiencles of injected gases that is proposed for FY91 is based on the premise that the solubillties of certain polymers are reduced by orders of magnitude in the presence of $\mathrm{CO}_{2}$. When properly placed, this precipitated polymer would effectively block the flow of injected gas from the high permeable zone and improve the sweep efficiency of the overall process. Because polymer injection is a well established procedure in the field, little difficulty is anticipated in applying this technology once a suitable polymer is found. So, atthough designated as a mid-term task, this technology could become a near-term solution to a difficult problem if a suitable polymer is quickly identified. This procedure would then be implemented in a fleld test as a means of transferring the fechnology to oll fleld operators.

\section{OBJECTIVE}

The objectives of this project are:

(1) for entrainers: address the critical issues that remain before their application in field trials can be justified. These issues include identifying the best class of compounds from which to choose the most cost effective entrainers, and identifying the best injection strategy for entrainers in gas flooding. For the latter, cycllc $\mathrm{CO}_{2}$ processes will also be tested for potential near-term applications;

(2) for other additives: evaluate unique approaches to improving sweep efficiency in gas flooding EOR processes. This year, precipitation of polymers and perfluorinated alkanes will be evaluated for potential mid-term applications; and

(3) for foam: initiate studies to evaluate foam flow behavior in radial corefloods. Although many have studled foam for moblity control, very few have actually studied the flow of foam under radial flow conditions--conditions more typical of the oll field environment.

\section{SCOPE OF WORK}

DOE's new Oil Research Program Implementation Plan recognizes that the application of $\mathrm{CO}_{2}$ will be fundamentally crucial in the near-term and mid-term time periods for recovering much of the mobile oil in the high priority geological classes (i.e., Open Shelf Platform, W. Texas). Problem: unfortunately, the effectiveness of currently applled technologies (EOR gas flooding) are often limited by low sweep efficiencies of the injected gases. The majority of tasks proposed for this project evaluate unique or untested approaches to improving mobility control and sweep 
efficlency. Use of entrainers for enhancing mobility control started at NIPER, and NIPER is currently the primary contributor to the evaluation of this technique. Use of perfluorinated alkanes has received very little attention in the literature. Also, the injection of polymers which are insoluble in the presence of $\mathrm{CO}_{2}$ to improve sweep efflclency remains untested by anyone, as far as we know. Each of these approaches will be tested in FY91.

Although most of the listed tasks are mid-term oriented, task 1 was inserted to help address DOE's near-term goals, and task 1 will be given the greatest emphasis for this project. As stated in DOE's Oll Research Program Implementation Plan, the near-term overall objective is to preserve access to defined, highi-potential classes that are rapidly approaching their economic limits with currently available technologles. Problem: mary of these reservoirs that could benefit from $\mathrm{CO}_{2}$ injection do not have access to cheap pipeline gas. Cyclic $\mathrm{CO}_{2}$ processes have demonstrated to be effective for these situations, but are virtually unknown by many of the independents operating marginal wells in targeted areas that are being shut in, abandoned, or plugged. NIPER has previously demonstrated that entrainers can improve mobility control in continuous $\mathrm{CO}_{2}$ Injection processes. If similar improvements are demonstrated for cyclic $\mathrm{CO}_{2}$ injection processes as proposled for FY91, recommendations will be made to test the process in the fleld. The opportunities for applying entrainers with cyclic as opposed to continuous injection of gas is greater because the economic restriction of being conveniently close to an existing $\mathrm{CO}_{2}$ pipeline is removed; also because the total investment is less, the process could be implemented by independent operators. The overall impast on domestic oll production rates should be favorable, and the rate of well abandonment for marginal wells should decrease.

Finally, a long-ter m orlented task on foam characterizallon was inserted, because it was felt the current practices of extrapolating linear flow experiments to typlcal radial flow regimes encountered in the fleld are unrealistic for foam. Very fow research laboratory studies on foam flow mechanisms are bared on actual radlal flow experiments, and very little work is currently being done in this area. NIPER and other laboratories have previously conducted many experiments on foam, and our past experience will be invaluable in gulding the planned experiments.

Product: In addition to the toplcal reports generated directly from inis prolect, those technologles developed i.inder this project that are found to be successful will be made avallable to the petroleum industry tinrough journal articles and presentatlons at technical meetings.

Iask 1. Determine and compare the benellalal effects of enirainers in cycllc co2 processes to those measured under llowlno conditlons. (Start Date: October 1, 1990. Completion Date: September 30, 1991.) (Near-term)

Several operating companies are currently trying the application of cycllc $\mathrm{CO}_{2}$ in their reservolrs. Certain entrainers have been found (project BE5B, FY89) to increase the range of 
hydrocarbon components extraotable with $\mathrm{CO}_{2}$ and improve the mobility control of injected fluld in flow-through systems. Laboratory studles will be oonduoted under this task to determine if a similar benefli is observed in a oyollo mode. All of the conditions will be the same as those for previous experiments, except the core will be shut in for a certain time period to allow the system to "snak." Provided substantlal benefits are evident, the process will be recommended for fleld trial.

Iask 2. Evaluate alternative compounds as entralners for aas lloeding. (Start Date: October 1, 1990. Completion Date: September 30, 1991.) (Mid-term)

It was determined in FY90 that other entrainer compounds have even greater potential for enhancing mobility control of injected gases in recovering oll than those previously tested. These compounds will be evaluated under this task for their ability to increase viscosity, improve mobility control, and enhance oll production. Vapor-Liquid Equilibrium (VLE) may also be determined for such unusually behaving mixtures as $\mathrm{CO}_{2}$-perfluorinated alkanes at a typical reservoir temperature. 1,1 addition to conducting the screening tests previously described (fluid density, viscosity, etc.), alternatlve methods of screening candidate entrainers will be explored.

Iask 3 . Test alternatlve Injection strategles to optlmize applleatlon pre: cedures for entrainers in gas flooding. (Start Jate: October 1, 1990. Completion Date: September 30, 1991.) (Mid-term)

Certain compounds, such as isooctane and 2-ethyl hexanol have been shown to enhance the mobility of $\mathrm{CO}_{2}$ in corefloods. However, effects of entrainer concentration, WAG cycles, and multiple entrainer slugs on performance have not been evaluated. This task is design to evaluate these factors based on coreflood experiments. Answers to these questions are critical to the application of this unlque technology in the field.

\section{Task 4. Laboratory experiments to Investlaate polymer preclpltatlon by} CQ2. (Start date: October 1, 1990. Completion date: August 31, 1991) (Mid-term)

Polymer solution properties will be studied first at ambient conditions. Experiments will be designed to determine the phase changes of polymer solutions with respect to the solution $\mathrm{pH}$ value. From these preliminary screening tests, a polymer will be selected for high pressure experiments to investigate polymer precipitation by $\mathrm{CO}_{2}$. In the high pressure experiments, the polymer solution will be mixed with high pressure $\mathrm{CO}_{2}$ gas inside a PVT cell and the precipitation will be determined by flowing the solution through filters. If the results are positive, coreflooding tests will be conducted to determine the effectiveness of this method for $\mathrm{CO}_{2}$ mobility control. 


\section{Iask 5. Assemble and make exeratlenal a sultably slzed radlal cere}

apparatus. (Start Date: October 1, 1990. Completion date: September 30, 1991.) (Long-term)

Small (6-In.-diameter) radlal coreflood experiments were conducted in FY90 to study varlous injection strategies to improve the injectlvity gradlent for foams in the near-wellbore region. However, because of the varled volume of foam, larger radlal cores are needed for extending these studies to an accurate investigation of foam flow properties in a radial environment. Under this lask, a larger diameter radlal coreflood apparatus will be constructed, and preliminary experiments will be conducted on foam flow to develop suitable methods for tracking the foam front. It is anticipated that in FY91 or FY92, a unique approach to describing radial foam flow, such as through chaos theory, will be developed and the laboratory capability developed under this task will be used to confirm the approach. Currently, most experiments are conducted in slimtubes and linear cores, and the results are mathematlcally extrapolated to radial flow. Micromodel studies of gas flow in two or three dimensions have shown that complexitles are considerable increased, and simpie geometrical extrapolation from linear to radial dimensions is not expected to adequately describe fluid flow patterns with gas and foam.

\section{DELIVERABLES}

Sep 91 Topical report describing the results nbtained from the entrainer studies.

Sep 91 Topical report discussing the feasibility studles with unique mobility control additives and with foam flow in radial cores.

\section{PLANNED STAFFING}

\section{Man-Years}

\section{Senior Engineer}

0.4

Senior Physicist

0.8

Research Chemist

0.3

Associate Engineer

0.2

Assistant Engineer

0.5

Senior Experimentalist

Total

\section{Prolect Leaders}

Frank Chung, Senior Engineer

Clarence Raible, Senior Physicist 
EQUIPMENT REQUIREMENTS

Viscosity measurement apparatus

Avallable New

Coreflooding apparatus

1

1

PVT apparatus

1

Data acquisition system

1

High-pressure electromagnetic viscometer 


\section{Be9. - three-phase relative permeability Research}

\section{BACKGROUND}

Multiphase flow is a common phenomenon in petroleum reservoirs. The initial or primary production from a reservoir may include gas, oil, brine, or combinations of the three. Later during the productive life of a reservoir, two-phasa flow occurs when a fluid such as brine is injected into a reservoir to boost production. Finally, if enhanced oil recovery techniques, such as chemical or immiscible gas flooding, are used to maximize hydrocarbon recovery, multiphase flow phenomena probably will occur. With multiphase flow, fluids compete for the same flow paths through reservoir rock. The additional resistance to flow is described by normalizing permeabilities for each of the flowing phases at each fluid saturation condition with respect to a base permeability. This measurement and normalization crocess yields relative permeability data. The FY91 research program is designed to build upon the pevious results for the project with emphasis on studying the relationships among pore and grain size distributions, trapping, tortuosity, and relative permeabilities. Existing two- and three-phase relative permeability apparatuses have been used in assisting several industrial clients.

The concept of relative permeability for two-phase flow is not new. Work on developing two-phase flow relationships probably began in 1859, and through the years techniques for using the results have been refined for estimating petroleum reservoir productivily and performance. Efforts to extend the techniques for three-phase flow began in 1941, but difficulties limited progress in this area. Keeping track of fluid saturations in a rock during three-phase, steady-state flow experiments was virtually impossible until the recent advent of techniques, such as $X$-ray and microwave attenuation, to monitor in situ fluid saturations directly during flow experiments. Correlations have been developed to predict three-phase flow effects from two-phase flow measurements, but such correlations are not always correct or accurate. The primary reasons for the limited knowledge with respect to three-phase flow systems are the scarcity of accurate threephase relative permeability laboratory data and laboralory measurement systems.

Three-phase flow characteristics are affected by rock properties, wettability, and hysteresis, among other factors. Because quantification of the relationships between rock properties and multi-phase flow behavior has not been completed, additional study is clearly required. The major problem that the availability of accurate measurement of multiphase relative permeability will solve is unrealistic numerical reservoir simulation. Relative permeability is a major input for reservoir simulation and if accurate data are not available for the behavior of fluids in the reservoir at actual reservoir conditions, a reasonable simulation cannot be made. Simulations are used by operating companies to decide how to develop a field, whether to conduct an improved recovery project, where to drill infill wells, to identify the cause of formation damages, and whether it is cost-eftective 
to continue production. NIPER uses the relative permeability equipment for industrial clients who must decide how to manage their reservoirs. Tests for industrial clients are conducted as closely as possible to actual reservoir temperatures and pressures. Thus, the equipment developed in this project nas an immediate applicability and provides a means of technology transfer to the petroleum industry.

NIPEA has conducted DOE-funded relative permeability research for the past 6 years. The objectives of this work have been to improve laboratory measurements of three-phase relative permeability so that reliable measurements are achieved and to investigate the influences of rock, fluid, and rock/fluid properties on two- and three-phase relative permeabilities. This work has yielded improvements in measurement techniques and equipment including the development of an $X$-ray and microwave scanning instrument for monitoring fluid saturations during relative permeability experiments; the development of a high-pressure coreholder that is semitransparent to microwaves; improvement in microwave technology for scanning rocks with thicknesses greater than 1 inch; and continual improvements in relative permeability measurement systems and techniques. Several models for computing three-phase flow characteristics have been evaluated using three-phase data from laboratory experiments conducted by Corey Naar-Wygal, NaarHenderson, and Stone. Of the models evaluated, none predicted the experimental data adequately, demonstrating that additional research is necessary. NIPER's two- and three-phase laboratory investigations have yielded important results. Three-phase experiments with Berea sandstone to demonstrate viscous effects on relative permeability showed variations in permeabilities as a result of variations in rock characteristics; brine and gas relative permeabilities were functions of the brine and gas saturations, respectively; oil relative permeabilities were functions of all three-saturations; and oil and water relative permeabilities were essentially independent of oil viscosity for viscosities in the 1 to $50 \mathrm{cP}$ range. Water relative permeabilities decreased with increasing wetting phase viscosity.

During FY89, NIPER investigated the effects of rock characteristics on relative permeabilities by comparing the results from experiments on Berea and Bentheimer sandstones. Relative permeabilities for the two sandstones were noticeably different, and these differences were attributed to variations in pore size distributions. Comparison of oil-brine flow test results showed that residual oil saturations for the Bentheimer sample were lower than those of the Berea sample; the range of mobile saturations for the Bentheimer sample were broader; and data from both samples were subject to hysteresis effects.

Recently, considerable industrial interest has been shown in determining when it is necessary to conduct relative permeability measurements at reservoir conditions and when it is sufficient to conduct the measurements at room temperature. NIPER is recognized by the industry as having considerable expertise is conducting relative permeability measurements at 
elevated temperatures and pressures and is pursuing a multiclient project to answer this question. Such a project will provide an excellent technology iransfer opportunity. Additional fechnology transfer will be accomplished by the preparation of journal articles subject to peer review and presentations for symposia.

\section{OBJECTIVES}

The objectives of this project are as follows:

1. To improve the reliability of laboratory measurements of two- and thrie-phase relative permeabilities for steady- and unsteady-state conditions in core samples.

2. To investigate the influence of rock, fluid, and rock-fluid properties on two- and threephase relative permeabilities.

\section{SCOPE OF WORK}

Project efforts will be concentrated in two primary areas: examination of mulual relationships among petrophysical properties and relative permeabilities; and improvement in three-phase relative permeability measurements. A homogeneous sandstone sample with absolute permeability in the 150 to $\mathbf{4 0 0}$ md range will be selected for complete characterization. The sample will be nearly identical to high-permeability samples tested during FY89 and FY90, except with respect to pore and grain size distributions. Two- and three-phase relative permeability experiments will be periormed on the sample in a systematic, highly controlled manner to produce high-quality data reflecting both drainage and imbibition cycles. Test results will be compiled and compared with those for the 600- and 2,000-md samples tested in previous years. It is anticipated that this work will build upon the foundation for the project established during FY89, ultimately leading to the development or verification of correlations between three-phase permeability and other rock properties.

Tasks to improve laboratory measurements will focus on comparing steady-and unsteadystate relative permeability measurements; comparing fluid saturation distributions from CT imaging with resistivity measurements to study variation in resistivity with saturation distribution; and improvements in laboratory automation. Finally, automation of the experimental system will continue with hardware and software modifications such that the laboratory computer will determine when coreflood flow conditions have reached steady-state conditions, then automatically scan the rock to determine the saturation distribution, and finally change pump rates to achieve a new steady-state condition. This automatic mode wi'" result in more reproducible determinations of steady-state conditions and more efficient time management. 


\section{Iask 1 Select and characterize sandstone sample in preparation for two-}

and three-ohase relative permeabllity experlments. (Start date: October 1990. Completion date: March 1991.) (Near-term)

One sandstone sample with absolute permeability in the 150 to $400 \mathrm{md}$ range will be selected for the FY91 experimental program. The petrophysical and petrographical properties of the sample will be characterized, including porosity, permeability, grain density, XRD and SEM measurements. Quantitative microscopic evaluation through petrographic image analysis will be conducted on thin sections of the rock sample to characterize pore and grain size distributions. Mercury injection and centrifuge capillary pressures will be measured. The wettability index for the sample will be fetermined from centrifuge capillary pressure results using the same oil and brine that will be used during flow experiments.

Iask 2. Conduct and analyze two- and three-phase relatlve permeabllity experiments. (Start date: November 1990. Completion date: September 1991.) (Near-term)

Two- and three-phase steady-state relative permeability experiments will be conducted under controlled ambient conditions. Electrical properties of the rock and $\mathrm{pH}$ of the effluent will also be measured as appropriate to provide additional insight into the process of achieving steady-state conditions. The overall objective of this task is to obtain high-quality data that can be related to other measurements for development of correlations. Results will be compared with those from FY89 and FY90.

Task 3. Conduct unsteady-state oll/water relatlve permeablilty trsts on the selected sandstone. (Start date: December 1990. Completion date: September 1991.) (Near-term)

A literature review of factors affecting unsteady-state relative permeability results will be conducted to determine guidelines for producing unsteady-state results which are comparable with steady-state results. Tests will be conducted at ambient conditions, and results will be compared with steady-state results from task 3 . Additional tests will be pertormed as necessary with higher viscosity oils or different injection rates and pressures to determine optimum test conditions for matching unsteady-and steady-state results.

Iask 4. Compare saturation dependent electrical proportles with saturation distrlbutions from CT Imaging. (Start date: January 1991. Completion date: June 1991.) (Near-term)

The flow of electricity through porous media is thought to be analogous to the flow of a fluid of zero viscosity. If so, the resistivity of a brine-saturated rock depends primarily on lengths of the shortest paths through the pores and on the rock's porosity rather than on permeability and pore 
shapes and sizes. Resistivity factors have been used to calculate effective pore lengths in brinesaturated rocks. Resistivities also have been correlated for partially saturated rocks as a function of water saturation, but such correlations are accurate only when the brine is uniformly distributed.

The effect of saturation distribution will be studied for Berea rock samples under various saturation conditions. Nonuniform saturations will be imposed through controlled dynamic flow experiments or by using a high-speed centrifuge. Electrical properties of partially saturated rocks will be measured, then the rocks will be CT scanned. Variations in electrical properties with variations in saturation distribution will be studied. This is important to field applications since resistivity is a common field measurement.

\section{DELIVERABLE}

Sep 91 Topical report describing two- and three-phase relative permeability results and their interrelationships.

\section{PLANNED STAFFING}

Senior, Research, and Associate Engineers

Man-Years

Technicians and Support Staff

1.3

Total

1.8

\section{Prolect Leader}

Daniel R. Maloney, Research Engineer

\section{EQUIPMENT REQUIREMENTS}

$X$-ray/microwave sources and detectors

Arallable New

Pumps for unsteady-state tests

1

Coreholder for unsteady-state tests 


\section{BE11A. - THERMAL PROCESSES FOR LIGHT OIL RECOVERY}

\section{BACKGROUND}

Stearnflooding of heavy oil reservoirs $\left(<20^{\circ} \mathrm{API}\right)$ is a mature technology and currently contributes nearly $7 \%$ of domestic daily oil production; however, heavy oll constitutes only about $10 \%$ of the total domestic petroleum reserves. This project was initiated to determine if steamflooding light crude oll reservoirs can be as successful as for heavy oil.

DOE is conducting steamflood fleld pilots in light oil zones in two reservoirs: one in the Elk Hills fleid in California, and the other in Teapot Dome (WY) field. Both projects demonstrate steamflooding in different environments. The California steamflood is in a highly permeable sand at a depth of $2,000 \mathrm{ft}$, and the Teapot Dome pilot is in a fractured consolidated tighter Shannon sand at $500 \mathrm{ft}$ depth.

NIPER research has shown that steamflooding previously waterflooded water-wet reservoirs is infeasible. Physical model 2-D steamflooding studies on previously waterflooded sands that are oil-wet, and of intermediate wettability, indicate that oil-wet reservoirs are prime candidates for steamflooding. Oil-wet reservoirs respond poorly to waterflooding and became stripper wells early in their productive life. Thus, oil-wet reservoir sands have high oil saturations as compared with water-wet reservoirs. Steamflooding in addition to supplying pressure and lowering the viscosity of the oil, changes the wettability to a more water-wet condition as part of the mechanism of light oil steamflooding. Thus, application of steam to oil-wet light oil reservoirs may help to maximize the economic producibility of this nation's oll resource-ihe major goal in DOE's Oil Research Program Implementation Plan. Steamflooding in even water-wet sands has been shown to reduce the oil saturation beyond what is achievable by waterflooding. Research at NIPER has shown that contrary to earlier simulation results, gravity override and fingering can be major problems.

During the past few years, NIPER has been analyzing oils and their thermal oil recovery potential. These oils were chosen because of their chemical composition. In FY90, NIPER analyzed base case 2-D steamfloods from a current California light oil steamflooding pilot. This study then correlated the composition of the produced oil with time and temperature (hot water vs. steam at various temperatures), analyzed potential override and fingering tendencies, and compared the results from light oil studies on proposed light oil steamflooding sites.

The ability to predict the effect of light oil steamflooding on a field scale requires a simulator that not only has thermal capabilities but also has mass transfer capabilities. Expansion of light oil steamflooding technology to the independent small producer will require a simulator in the public domain that has this capability. The personal computer-based semianalytical predictive models 
developed for heavy oil need to be analyzed for their adaptability in predicting behavior of steamflooding light oils.

Transferring the technology resulting from the project will be accomplished by reports on the results of the work prepared for the DOE, participation in symposia and meetings of professional societies, and publication, as warranted, in professional and trade journals. Personal contacts, as requested, will be made with representatives of the petroleum industry in fulfillment of requesis for information and data about the work.

\section{OBJECTIVES}

Specifically for FY91, the objectives are as follows:

(1) determine the effect of steam temperature on composition of the produced oil and residual oil saturation (hot water vs. steam at various temperatures). Determine potential override and fingering tendencies in a 2-D model using oil and sand from Teapot Dome (WY) field. Compare Teapot Dome results with oils analyzed from proposed light oils steamfloods.;

(2) examine the applicability of the semianalytical thermal predictive models for applicability in evaluating light oil steam flood potential;

(3) construct a new multidimensional steamflood physical model; and

(4) support the DOE in its cooperative elfort with Venezuela in thermal technology transter by participating in the Annex IV meetings that are scheduled twice a year.

\section{SCOPE OF WORK}

Iask 1. Analyze seml-analktical numerlcal predlctlve models (Start date: October 1990. Completion date: December 1990.) (Near-term)

This task is designed to analyze the current semi-analytical thermal predictive models for their applicability for use in evaluating light oil steamflood potential. Based upon the analysis, a compositional package could be added in FY 92. This simulator could be used to screen midcontinent reservoirs for light oil steamflooding.

Iask 2. Compare the oll recovery efflciency of hot water versus steam from the 2-D model using Teanot Dome core and oll. (Start date: December 1990. Completion date: July 1991.) (Near-term)

This task is designed to analyze base case 2-D steamfloods using field sand and oil from Teapot Dome. This study will be conducted to study the produced oil composition with time and temperature (hot water vs. steam at various temperatures), and potential override and fingering tendencies in this field pilot. The data collected in this task will be compared with previous light oils that have been analyzed for their potential recovery by steamflooding. Results from this task can be immediately used by operators of this field pilot. 
Iask 3. Desian of a multudimensional steamflood physical model. (Start date: October 1990. Completion date: September 1991) (Mid- to long-term)

This task is proposed based on the results of task 5 of BE11A in FY90. A scaling study and analysis of the current 2-D model was conducted to determine whether a new design is needed. A multidimensional steamflond physloal model will be constructed in FY 91 and FY92 to add to NIPER and DOE's capability to conduct research in steam EOR. This task will be implemented in cooperation with BE11B.

Iask 4. Support the DOE in lis cooperative effort with Venezuela by presenting the results of this project at the Annex IV meetings, (Start date: November 1990. Completion date: April 1991.) (Near-term)

This task is designed to support DOE in their technology exchange with the Venezuelan Ministry of Energy and Mines to increase oll production by thermal methods. Activities within this task include attendance at joint meetings, participation in joint discussions, and presentations of results (both oral and written) obtained from light oll research performed in this project.

\section{DELIVERABLES}

May 91 Summary report on the activities under this project for inclusion In the annual report of the Annex IV meetings.

Sep 91 Status report that describes research conducted on light oll in support of thermal processes for llght oil recovery.

PLANNED STAFFING

$\begin{array}{lc} & \text { Man-Years } \\ \text { Serior and Research Chemists } & 0.45 \\ \text { Research and Associate Engineers } & 0.7 \\ \text { Technicians } & 0.8 \\ \quad \text { Total } & 1.95\end{array}$

Project Leader

David K. Olsen, Senior Chemist 


\section{EQUIPMENT REQUIREMENTS}

\section{Avallable New}

Computer

Support equipment for new steamflood model 1

Data backup system 


\section{BE11B. - THERMAL PROCESSES FOR HEAVY OIL RECOVERY}

\section{BACKGROUND}

Steamflooding of heavy oil reservoirs $\left(<20^{\circ} \mathrm{API}\right)$ is a mature technology and currently contributes nearly $7 \%$ of total U.S. daily oil production. Currently, the majority of the Nation's steam injection projects are concentrated in California where most of the oll is produced by major operators. The goal of making this technology avallable to small independent operators has been slow in developing because the independents do not have access to the technology heid by the major operators and must rely on information dispersed throughout the public domain.

To assist in technology transfer to independent oll producers, NIPER is developing an operator's guide to thermal EOR based on an assessment conducted during FY90 on Callfornia's ongoing thermal operations. This undertaking is much like the early SPE papers and waterflooding papers prepared as part of the technology transfer conducted in the 1950's by the U. S. Bureau of Mines, Bartlesville, Oklahoma, to help independent operators successfully implement waterflooding technology.

Heavy oll reservolrs usually have a high oll saturation, and steam can effectively reduce the viscosity by orders of magni.ude. However, the differences in viscosity and density between steam and heavy oll reduces the sweep efficlency of the process. Thus, close spacing and increased sweep efficiency are critical in maximizing oll production.

The NIPER 2-D laboratory physical model is capable of evaluating specific aspects of steam foam and other proflle modifying agents needed to help alleviate sweep efficiency problems. Future advances requires a different model to study the process. A study was undertaken as task 5 in BE11A during FY90 to evaluate the model, propose scaled experiments, and suggest alternative physical models that could be used in future research. The proposed model is a compromise between desirable features and cost, while permitting research on other aspects of thermal reciovery of heavy oil to continue. Assembly of the model over the next 2 years is achievable under the current funding level. Increased funding would permit the model to be operable in less time. The new model will allow us to resume evaluation of steam diverters and be more representative of actual field conditions, including the chemical and physical processes occurring at the vapor/liquid-solid/liquid interface.

Effective technology transfer of the findings of this research to the petroleum industty will be a major goal o this project. Results will be reported to the DOE as described in the section of this plan on Deliverables. In addition, the project leader and members of the project team will prepare peer-reviewed technical papers about the project for professional society meetings and publication in the scientific literature. 


\section{OBJECTIVES}

Speolfically for FY91, the objectives are as follows:

(1) as an addition to the thermal (steam) fleld operators' guide sections prepared in FY90, the costs, sample engineered analysis, schematics, and equipment needed for Implementation of a steamflood by an independent operator will be prepared in a format that can be used by independent operators to help assess the economic feasibility of implementing a thermal EOR process;

(2) advance the current numerical laboratory thermal simulator to assist in the analysis of laboratory experiments using both vertical and horizontal steam injection; and

(3) construct a new multidimensional steamfiood model.

\section{SCOPE OF WORK}

Iask 1 . Complle a supplement to the steamtlood eperators qulde publlsh ed In FY90. (Start date: October 1990. Completion date: June 1991.) (Near-term)

This task is designed to support DOE in near-term technology transfer to independent operators by publishing a topical report that incorporates the status report on the thermal (steam) fleld operators gulde prepared in FY90. Potentlal topics in addition to those of FY90 include costs, schematics, and equipment listings for implementation of thermal (steam) EOR. Also, a section of this report will provide an analysis of current screening criteria and describe the development of a system to help the independent operator assess the feasibility of using stearn to increase production. In addition, this task will develop a spreadsheet model that may assist the operator in assessing the economic feasibility of implementing steamflooding.

Task2. Desian of a mullidimenslonal steamflood physical model. (Start dato: October 1990. Completion date: September 1991.) (Mid- to long-term)

This task is proposed based on the results of task 5 of BE11A in FY90. A scalling study and analysis of the current 2-D model was conducted to determine in FY90 whether a new design is needed. Based upon the funding level, a multidimensional steamflood physical model will be added to the capability of NIPER and DOE to conduct research in thermal EOR.

Iask 3. Develooment of Impllalt version n numerical laboratery thermal simulater (Start date: October 1990. Completion date: December 1991.) (Near- to mid-term)

This task is designed to advance the current numerical laboratory thermal simulator to an Implicit version running on a personal computer. This will allow simulation of current and future laboratory thermal displacement experiments injecting steam in both vertical and horizontal orientations. No PC level compositional thermal simulator is currently available. A public domain 
version will be delivered in the near future based on the effort allocated for this and subsequent tasks.

\section{DELIVERABLES}

Jun 91 Toploal report on steamflood operators' guide.

Sep 91 Status report that describes research conducted in support of thermal processes for heavy oil recovery (numerical laboratory thermal simulator and design of a multidimensional physical model).

\section{PLANNED STAFFING}

\begin{tabular}{lc} 
& Man-Years \\
Senior Chemists & 0.3 \\
Research and Associate Engineers & 0.7 \\
Technicians & 0.3 \\
Consultant & 0.1 \\
Total & 1.4 \\
Prolect Leader & \\
\multicolumn{1}{c}{ David K. Olsen, Senior Chemist } & \\
EQUIPMENT REQUIREMENTS & Avallable \\
New 2-D steamilood physical model & 1 \\
Thermal heat flux sensors & 1
\end{tabular}




\section{BE12. - IMAGING TECHNIQUES APPLIED TO THE STUDY OF FLUIDS IN POROUS MEDIA}

\section{BACKGROUND}

This project is in support of reservoir description R\&D, especially in the areas of reservolr chemistry, physics, and rock-fluid interactions at the mioro- and maoroscopic scales.

The techniques developed in this project are being used in oharacterizing pore to core scale helerogeneities for BE1 and BE9 and, together with fechniques developed in BE9 are being applied to solve formation damage and production problems for several oll producers (identities of the producers remain confidentlal as agreed with these producers). Over the next two years these techniques will be used to provide fleld RD\&D support to assist in the characterization of pore structures and surtaces, rock/fluld Interactions, and residual oil distributions for a planned alkaline-surfactant-polymer field project and a potential polymer flooding project in two priority reservoir classes in the midcontinent area. These techniques will also be applied to identify dominant recovery processes associated with each priority reservoir class. Besides the above near- and mid-term goals, the long-term goal is to apply the techniques developed in this project to study oil trapping and recovery mechanisms, so that new and novel enhanced oll recovery processes can be developed.

Considerable progress has been made in rock-fluid imaging technology to quantify the impact of rock heterogeneitles on the effectiveness of oll recovery. Accomplishments of this program over the past several years have generated results directly applicable to increased oil production in the near-term. Some of these accomplishments are as follows.

Development of a computerized image analysis system to be used for petrographic measurements. This system allows rapid and automatic measurements of pores, pore throats, and grain sizes in thin sections prepared from reservoir rock and is used to calculate porosity and permeability values. The system can be used with samples from cores, sidewall cores, or drill cuttings. This technique will allow producers to determine the permeability and porosity of reservoir rock without expensive coring and core analysis. NIPER has used this technique to solve formation damage and production problems in oll and gas reservoirs for several oil producers. Industry is currently funding cooperative efforts and additional industry involvement is actively being solicited.

Computerized tomography (CT) technology, already widely used in the medical field, has been gaining acceptance in petroleum research as a powerful tool for nondestructive measurements of variations in rock properties and fluid saturations in reservoir rock. Using CT scanners avallable at area hospltals, research work has been ongoing at NIPER for more thari 4 years to investigate core heterogeneities and fluid flow in cores. By interfacing the CT scanner acquired in 1989 with the computerized Image processing and analysis system already 
developed, quantitative measurements of oil and brine spatial saturation distributions have been performed during flow experiments through core materials. At present, studies of flow processes are performed at ambient conditions, but operators are often interested in imaging recovery processes occurring at pressures and temperatures similar to those encountered in the reservoirs being studied. NIPER has performed CT-scanning of cores for industrial clients, either as special projects, or as part of other core measurement contracts where CT images are an integral part of the process to select representative core plug samples from whole cores. This technique is useful in determining heterogeneities in cores and their influence on oil recovery processes. Technology transfer has been acccmplished by NIPER researchers through peer-reviewed publications and presentations of CT-generated information.

Development of nuclear magnetic resonance imaging (NMRI) is another nondestructive imaging technology transferred from the medical field to the petroleum industry. It is used to image fluids within cores. NIPER has modified an in-house NMR spectrometer. The small bore of the NIPER spectrometer, and other instrument characteristics, should allow image resolutions down to 10 microns. By comparison, NMRI instruments available for medical purposes have resolutions of the order of 500 microns. The high resolution achievable allows visualization of the effect of rock/fluid interaction on oil, water, and gas distributions within pore spaces of small core plugs. Such a capability would help in understanding oil displacement processes taking place at the pore level and is essential in understanding the mechanisms of various oil recovery processes. The NMR instrument has generated images of fluids in cores and beadpacks with resolutions to 125 and 25 microns, respectively. The present limitations to achieving finer resolution are: (1) the computing power of the NMR spectrometer computer, (2) delays caused by demand on multiuser MicroVAX computer, (3) the image processing station, and (4) the speed of the data transmission link between these three computers. A single, high-speed, state-ot-theart graphics work station would reduce the turnaround time tenfold between the NMR highresolution, 3D image acquisition directly connected to the NMR spectrometer and final image output. NIPER is on the forefront of developments in the area of NMR imaging in, (1) resolution, (2) distinguishing oil and water phases, and (3) image processing.

Pore level fluid displacements using micromodels is a new technique that has been developed at NIPER using thin-slab $(3 \mathrm{~mm})$ micromodels bult from of sancistone samples. Porelevel fluld flow and fluid displacement processes for oll, gas, and water phases have been observed by optical microscopy. This technique, combined with flow experiments performed on cores, is used to Improve the understanding of mechanisms by which various oll recovery processes remove oll from reservolr rock. This technique can help in the design of an op!tmum recovery process for a given reservoir rock by enabling observations, at the pore level, of the effects of various flow regimes, fluld properties, and injected chemicals on oil mobilization. 
Integration of the above rockffluid imaging techniques for understanding effects of smallscale rock heterogeneities on oil trapping in reservoir rocks for processes taking place at conditions relevant to oil recovery is one of the unique features of this project. The integration of these techniques enables a more definitive assessment of the roles of heterogeneities in affecting oil entrapment, fluid flow and fluid saturation distribution. This integration is described in a paper on the effect of small-scale heterogeneities on fluid distribution, to be presented by NIPER researchers at the 1990 SPE Annual Meeting. Several oil and service companies have facilities for one of the rock-fluid imaging techniques, but few have all these techniques for integrated investigations. The combination of these methods enables NIPER to investigate the effects of various scale of heterogeneities (pore to core scale) on oil recovery efficiency.

\section{OBJECTIVES}

1. To develop a methodology to derive reservoir engineering parameters from petrographic, computed tomography (CT) scanning, and nuclear magnetic resonance (NMRI) images.

2. To apply state-of-the-art technology as it is developed to provide field support to characterize high-priority reservoirs.

3. To transfer the newly developed technology through an industry consortium, organized to help plan, review, and participate in the research. Opportunities for industry bilateral cooperation in the research will be pursued.

\section{SCOPE OF WORK}

In addition to applying these techniques to support BE1 and BE9, they will also be applied to support the reservoir characterization effort of an alkaline-surfactant-polymer field project and a planned polymer flooding project. Both of these projects are to be implemented in priority classes of reservoirs. Active participation in the support of the field work (heterogeneity description) on the selected priority reservoirs described in the PIP, as they are selected, will be pursued. It is necessary to improve the efficiericy of image-handling capabilities of both the CT and the NMRI systems to reduce the time between the initiation of data acquisition and resultant fluid saturation maps of cores. This will increase capacities of both CT and NMRI instruments and increase efficiency in processing samples. These capacity increases are necessary to make these technologies more attractive for industry utilization to optimize oil recovery processes in the nearterm. Technology transfer will be accomplished by the preparation of DOE reports, journal articles and presentations for symposia.

Applying imaging techniques to the study of fluids in porous media to determine oil trapping and release mechanisms in EOR processes will contirue. Study of the effect of microscopic-scale 
rock heterogeneities on the trapping of oil in core samples will be expanded to reservoir pressures. The existing experimental setup will be modified to handle high pressure flulds used in immiscible $\mathrm{CO}_{2}$ and WAG processes. Scaling procedures from microscopic to core plug to whole core will be utilized in experimental design and data analysis. The objectives of these experiments are: (1) improving the reliability of core measurement data used in oil recovery simulations aiding the identification of high priority reservoirs; (2) to quantify and to observe directly and rapidly the various flow regimes and mobilization of trapped oil in EOR processes and improved waterflooding, to aid in the selection of optimal recovery process for a priority reservoir class; and ( 3 ) to develop fundamental understanding needed to identify novel techniques for recovering immobile oil. The CT scanner will be used to observe fluid distributions for both miscible and immiscible floods in heterogeneous 2-in.-diameter cores under reservoir pressures. Pore geornetries and fluid distribution in locations where oil trapping takes place will be studied by means of computer image analysis of thin sections and high resolution NMRI. Using these techniques, correlations and scaling procedures will be derived for the laboratory corefloods measured. Oil trapping and removal under various flow regimes will be quantified for rock from field projects being implemented in high priority reservoir classes.. (Near to mid-term)

Iask 1. Provide suppont to fleld projects (Start date: October 1990. Completion date: September 1991.) (Near-term)

Apply computerized petrographic and CT imaging ter.hniques to characterize cores from the reservoir chosen for the alkaline-surfactant-polymer and polymer flooding (if approved) projects. Support the field work (heterogeneity description) on selected priority reservoirs as described in the PIP.

Task_2. Perform high-pressure corefloods using CI. (Start date: October 1990. Completion date: August 1991.) (Mid-term)

Perform high-pressure coreilood experiments to simulate immiscible $\mathrm{CO}_{2}$ and wateralternate-gas (WAG) recovery processes. The effect on trapping due to rock heterogeneity; oil, gas, and brine properties; and flow regimes will be studied. The rock will be characterized using CT, SEM, and by computer-assisted petrographic analysis. Acquisition of a high-pressure core holder, displacement purnps, automated flow control and data acquisition, and supporting hardware and software will be required. Increasing the transfer and processing speed of CT images and the size of mass storage for real-time monitoring of the corefloods is necessary. Published scaling laws applied to heterogeneous systems will be used in the design of experiments and analysis of results. Evaluate the possibility of using the dual energy scanning 
capability of the Somatom II scanner for multiphase saturation measurements and displaying them in three-dimensional form.

Iask 3 Improve the NMBL resolution and data acaulsitlon speed. (Start date: October i990. Completion date: September 1991.) (Long-term)

Improvements such as adding a workstation for faster image processing and modifying the existing NMR spectrometer hardware and software will be performed to allow application of this technique to study effects of rock/fluid interactions (wettability) on fluid trapping, oil release mechanisms, and residual oil saturations.

\section{DELIVERABLES}

Sep 91 Status Report-summarize the field and laboratory support efforts using techniques developed in this project.

Sep 91 Topical Report - to include (1) a discussion of equipment medifications, equipment capabilities and operational procedures; (2) experimental design for corefloods conducted in conjunction with CT or NMR imaging; and (3) results of coreflood experiments.

\section{PLANNED STAFFING}

Senior and Research Physicists

Man-Years

Senior, Research, and Associate Engineers

1.6

Technicians and Support Personnel

Total

\section{Project Leader}

Liviu Tomutsa, Research Physicist

\section{EQUIPMENT REQUIREMENTS}

CT Scanner
NMR
SEM
Micromodel system
High-pressure coreholder
Positive-displacement pumps
Work station for NMRI
X-Ray tube

Avallable New

1

1

1

1

2

1

1 


\section{Euels Research}

The primary emphasis in Fuels Research (FR) is to develop information which will allow the use of heavy or unconventional feedstocks with nearly the same efficiency as is enjoyed with use of light, sweet crudes. These heavier feedstocks are being introduced into processing streams at an increasing rate as supplies of light stocks diminish. These heavier feedstocks are expected to be a substantial part of the refinery feedstocks in the future. Unfortunately, heavier crudes vary considerably in composition. They also usually contain higher concentrations of undesirable chemical constituents which cause problems throughout the refining and end use sequence.

The DOE, through its Advanced Extraction and Process Technology (AEPT) Program, is supporting research to obtain basic data for the technology associated with heavy crudes and other alternative fossil-related feedstocks. NIPER's Fuels Research Department has two projects under AEPT in the Base Program.

The research work in project BFR2 emphasizes the development of methodology to analyze problem components such as metal-containing compounds and compounds which contribute to coke formation. With sufficient data and understanding, processes can be developed which will reduce the risk and increase the efficiency of processing these feedstocks to transportation fuels.

In project BFR3, thermodynamics research continues based on assessment of needs for specific data. Pure compound work will continue on organic nitrogen compounds and compounds which contain two heteroatoms.

A complete description of the two projects in the Fuels Resuarch Base Program follows. 


\section{BFR2. - DEVELOPMENT OF ANALYTICAL METHODOLOGY FOR ANALYSIS OF HEAVY CRUDES}

\section{BACKGROUND}

The trend toward the use of heavier feedstocks by domestic refineries is well documented. Conversion of these higher molecular weight feedstocks to liquid transportation fuels requires continually deeper conversion of the residual materials. The heavier feeds and need for deeper conversion have resulted in increased problems in both refining and in product quality. The proposed analytical technicue development addresses both the refining and product quality problems.

In FY 1990, NIPER began to address the coking and heteroatom deposition tendencies of compound classes in petroleum residues. This work will be continued in FY1991. Coking or carbon deposition is a common occurrence in many refining processes, particularly those employed for upgrading distillation residues. Carbon deposits typically also contain portions of sulfur, nitrogen, and metallic elements origirially present in cumpounds which contributed to coke formation. In connection with catalytic processes, these deposits are particularly harmful because they result in loss of catalytic activity. Catalyst regeneration processes are not effective in removal of metals codeposited with carbon, and sulfur and nitrogen oxides in regeneration gases require removal for environmental reasons. In this project, the relative tendencies of compound classes to (1) form coke and (2) codeposit heteroatoms will be determined and correlations will be derived relating coking tendencies to chemical composition. This information will aid in optimizing refining processes by reducing the amount and impact of coke formation.

The second research area proposed is speciation of metal-containing compounds in petroleum residues. Development of a process for removal of metals from heavy crudes would greatly improve their compatibility with existing refineries as well as the yields of distillate products obtained. Development of demetallization processes would be aided by analyses which define the types and general structures of metal complexes present in a given crude. Analytical research toward development of suitable methods for this will be continued.

The final analytical technique area proposed for further development is a continuation of the means for identification of specific compounds or compound classes responsible for problems in refining and/or product quality. The usual approach for determining these components, typically present at minor or trace levels, involves preconcentration and/or removal of interferences via HPLC or other liquid phase separations, followed by gas chromalography (GC), mass spectrometry (MS), or combined GC/MS determinations. Chernical derivatization techniques are often employed to improve the specificity of the analysis and/or the GC behavior of the components of interest. Prior work under this project ied to significantly improved methodology 
for oxygen-containing compounds including phenolic species, multiple-hydroxylated aromatic compounds, and carboxylic acids.

\section{OBJECTIVES}

Generally, to identify compounds or classes of compounds with signiflcant positive or negative effects on crude oil and/or product properties and characteristics and to develop methods for their determination in conventiona! or low grade petroleum and syncrudes.

Specific objectives for FY91 are: (1) to determine relative carbon forming (coking) tendencies of compound classes in petroleum and to relate coke yield and heteroatom content to chemical structure, (2) to develop procedures for breaking associates formed between metal- and nonmetal-containing compounds which will ultimately lead to methods for isolation and identification of metal-containing compounds in petroleum, and (3) to further develop mass spectrometric methods for analysis of nitrogen and sulfur corinpounds in petroleum.

\section{SCOPE OF WORK}

High performance liquid chromatography (HPLC) will be used to generate fractions of varying chemical composition for carbon residue determinations. Micro carbon residue (MCR) testing will be carried out using the standard ASTM method D 4530. Elemental balances will be determined for $\mathrm{N}, \mathrm{S}, \mathrm{Ni}$, and $\mathrm{V}$ throughout the fractionation and carbonization steps. Fractions ubtained from preliminary separations in FY90 will be subfractionated further into more discrete compound groups. Results from their analysis will be used to expand and refine earlier correlations concerning carbon and heteroatom deposition properties of compound classes in petroleum resids.

Dissociation of aggregates comprised of metal and nonmetal-containing compounds in resids will be attempted using a combination of HPLC separations and chemical treatments. Fractions alieady appreciably enriched in $\mathrm{Ni}$ - and V-containing compounds will serve as starting materials. The degree of dissociation achieved by any given process will be determined from elemental analysis of the resulting fractions/products and, if warranted, visible spectrophotometric and MS analysis.

Differentiation of primary, secondary, and tertiary aromatic amines will be attempted by acylation under conditions sufficient for quantitative conversion of all N-H moieties to the corresponding trifluoroacetyl amide. The reaction product will be analyzed by GC/MS. Preliminary work has demonstrated conversion of pure primary aromatic amines (e.g., aniline) to

ditrifluoroacetyl derivatives and secondary aromatic amines (e.g., diphenylamine) to monotrifluoroacetyl derivatives. Tertiary amines (e.g., pyridine) do $r$ of acylate. The proposed work will evaluate the feasibility of this approach for analysis of base fractions from actual refinery 
streams containing aromatic amines (e.g., cat cracked and hydrotreated products). In addition, the degree of derivatization achieved for hindered amines (e.g., 2,6-dialkylanilines) and potentlal for interference from other compound types will be assessed.

The potential advantages of GC/MS analysis of sulfur compounds as their trifluoroacetyl derivatives will also be explored. In particular, the effectiveness of acylation toward preventing conversion of thiols to disulfides via air oxidation will be investigated.

Iask 1 - Coklng tendencles of compound classes. (Start date: October 1990. Completion date: September 1991)

Fractions exhibiting unusually high carbon forming or heteroatom deposition iendencies will be further fractionated using existing methodology (see NIPER Report No. 452, December 1989). The resulting subfractions will undergo MCR testing and elemental analysis to determine their relative contributions to that of the whole material. They will also undergo spectroscopic analysis to determine compound types/classes present. The above data will be used to arrive at more detailed correlations of coke formation versus chemical structure than possible from preliminary fractions.

Iask 2. Dissoclation and Isolation of metal-contalning compounds. (Start date: October 1990. Completion date: September 1991)

Existing metal-enriched fractions obtained from HPLC separations on a 2-(4pyridyl)ethylsilica will be further separated using a different type of HPLC column. In addition, isolation of metal porphyrins from those fractions via precipitation with $\mathrm{TiCL}_{4}$ or other agents will be attempted. If sufficiently pure metal-containing fractions are obtained, they will be analyzed by spectroscopic methods, including MS with microprobe sample introduction. In addition, their ablity to reassoclate with nonmetal-containing compounds of varying type will be determined by size exclusion HPLC.

Insk 3 . Development of GC/MS mothods for nitrogen and sulfur com: pounds. Start date: October 1990. Completion date: September 1991)

Five to $10 \mathrm{mg}$ quantities of whole base fractions and subfractions enriched in primary aromatlc amines will be acylated by heating for one hour at $80 . \mathrm{C}$ in the presence of $0.4 \mathrm{~mL}$ trifluoroacetic anhydilde and $0.5 \mathrm{~mL}$ of a $0.8 \mathrm{M}$ 4-dimethylaminopyridine-dichloromethane solution. A wide varlety of fractions from light cycle olls, coal llquids, and hydrotreated streams is avallable. The abundance of primary versus secondary versus tertlary amines from GC/MS analysis of the acylation products will be compared with that predicted from titration and other analyses. Also, prominent structural types for each class of amine present in the various samples will be determined. 
Aliquots of pure aromatic and aliphatic thiols will be acylated as above and their GC/MS properties determined. The stability of the derivative will be assessed from reanalysis over a period of several days. Acidic sulfur compounds will be isolated from selected crude olls via caustic extraction, acylated, and analyzed by GC/MS if preliminary results warrant such an effort.

\section{DELIVERABLES}

Sep 91 Task 1 - Topical report

Sep 91 Task 2-Topical report

Sep 91 Task 3 - Topical report

\section{PLANNED STAFFing}

Senior Chemist

Man-jears

Research Chemist

Assistant Chemist

Techrisian

Total

\section{Project Leader}

John B. Green, Senior Chemist

\section{EQUIPMENT REQUIREMENTS}

High pertormance liquid chromatography

(HPLC) systems, also HPLC accossories:columns,

specialized detectors, column packing apparatus 6

Rotary solvent evaporators $\quad 4$

Gas chromatographs (GC) with supporting intelligent intertacing 5

MS.80 GC/MS

MS-50 field ionization, fleld desorption,

olectron impact mass spectrometer

HP-5970A mass selective GC delector

Flame/graphite furnace atomic adsorption

spectrophotometer 1

Infrared spectrophotometer 1

270 MHZ NMR 


\section{BFR3. - THERMOCHEMISTRY AND THERMOPHYSICAL PROPERTIES OF ORGANIC NITROGEN- AND DIHETEROATOM-CONTAINING COMPOUNDS}

\section{BACKGROUND}

The average API gravity of the crude oil run to stills in the United States dropped from approximately 34.2 in 1978 to 32.2 in 1987. The trend continues today. That drop in gravity has been accompanied by an equivalent increase in the amount of petroleum coke exported by the United States. When the cost of the oil imported and the price obtained for the coke are compared, it accounts for approximately one billion dollars of the trade balance deficit per year. The heavier crudes contain more carbon, oxygen, sulfur, and nitrogen (polyoyclic aromatics and heteroatom-containing compounds) than the benchmark West Texas intermedlate. These heteroatom-containing compounds are difficult to remove. Processing of crudes containing Increasing levels of oxygen, sulfur, and nitrogen using present-day technology has produced fuels with high heteroatom contents and a tendency loward instability. The refractory nature of the heteroatom-containing compounds is the main reason for the increase in coke production. The full utilization of heavy oil to make quality transportation fuels requires an understanding of the chemistry and the thermodynamics of adding hydrogen to the feedstocks. The major goal of this research project is to aid in that understanding.

The design of processes to convert alternative refinery feedstocks (heavy crudes, heavy ends, oil shale, tar sand liqu ids, and coal liquids) into products that can be used in current technologies without severe energy penalties and/or harm to the environment requires thermodynamic data. Applications of these data include determination of optimum reaction sequences; optimum reaction compositions, temperatures, and fressures for desired conversions; cooling/heating requirements for reaction vessels; capacity of heat exchangers; and size, strength, and complexity of separation vessels.

The data available for light petroleum, which contains a relatively narrow set of classes of compounds, have permitted the design of processes to produce desired products with high efficiency. The precision and accuracy obtained in the measurements on the components of light petroleum performed by this and other research groups was such that they have become part of the "permanent" literature and are used with confidence within industry in process design and development. However, as noted above, the alternative feedstocks contain substances of drastically different and miore varied chemical structure, and the procedures cieveloped for light crudes are often not applicable.

The thermodynamic data base for the components of altcrnate crudas is severely limited. Efficient processing of such crudes requires research programs that study the different compound types present. The programs must include larger, and often more reactive, molecules 
than before, studied to higher temperatures, while generally maintaining the accuraoy and precision of the results for light petroleum components. This laboratory maintains its position at the cutting edge of technology in thermodynamio property measurements, with significant progress recently made in projects such as the one desoribed here.

Thermodynamics research at NIPER in this area is currently funded by three different DOE Office of Fossil Energy programs: Advanced Extraction \& Process Technology (AEPT), Advanced Research section of Coal Liquefaction (AR/CL), and Basic Energy Sciences Offlce of Energy Research (OER). The crosscutting nature of the research funded by the AEPT, AR\&TD, and OER sections of the Office of Fossil Energy is summarized in Exhibit 1. The results obtained In the thermodynamics research programs are applicable across the full range of fossil fuel sources from heavy petroleum through oil shale and tar sands to the utilizatlon of coal.

Topical reports generated in these projects have demonstrated that some of the hydrogenation reactions among heteroatomic species are reversible over a wide range of processing conditions. Consequently, a knowledge of the thermodynamic equilibria among species is essential for the proper interpretation of reaction data, for comparing different catalysts, and for accurate modeling of the overall reactions for such processes as hydrotreating or hydrocracking. Thermodynamics can be used to ascertain the relative stabilities of proposed intermediates, to determine if a given reaction is possible (and, if not, whether shifting the reaction conditions will make it so), and to determine specifically which reactions are reversible.

This section of the NIPEA research program, funded by AEPT, is concerned with organic nitrogen- and diheteroatom-containing compounds. The program represents, in part, the results of the comprehensive state-of-the-art assessment undertaken in FY86. Thermodynamic considerations arising from recently developed and current information on heteroatom compounds are being used to interpret the differences observed between heavy crudes and the products arising trom their upgrading. The research program goals include answering the following three key questions concerning heteroatom removal reactions:

1. What are the reaction networks? Alternatively, what are the stable intermedlates formed?

2. What are the reactivities of the various classes of nitrogen-containing compounds?

3. Are the reaction networks and commonly accepted generalities about reactivities valid for broad groups of catalysts?

Topics of investigation include: the role of equillbria, the interplay of thermodynamics and kinetlcs, and the effect of cholce of catalyst on the aromaticity of the final products. 


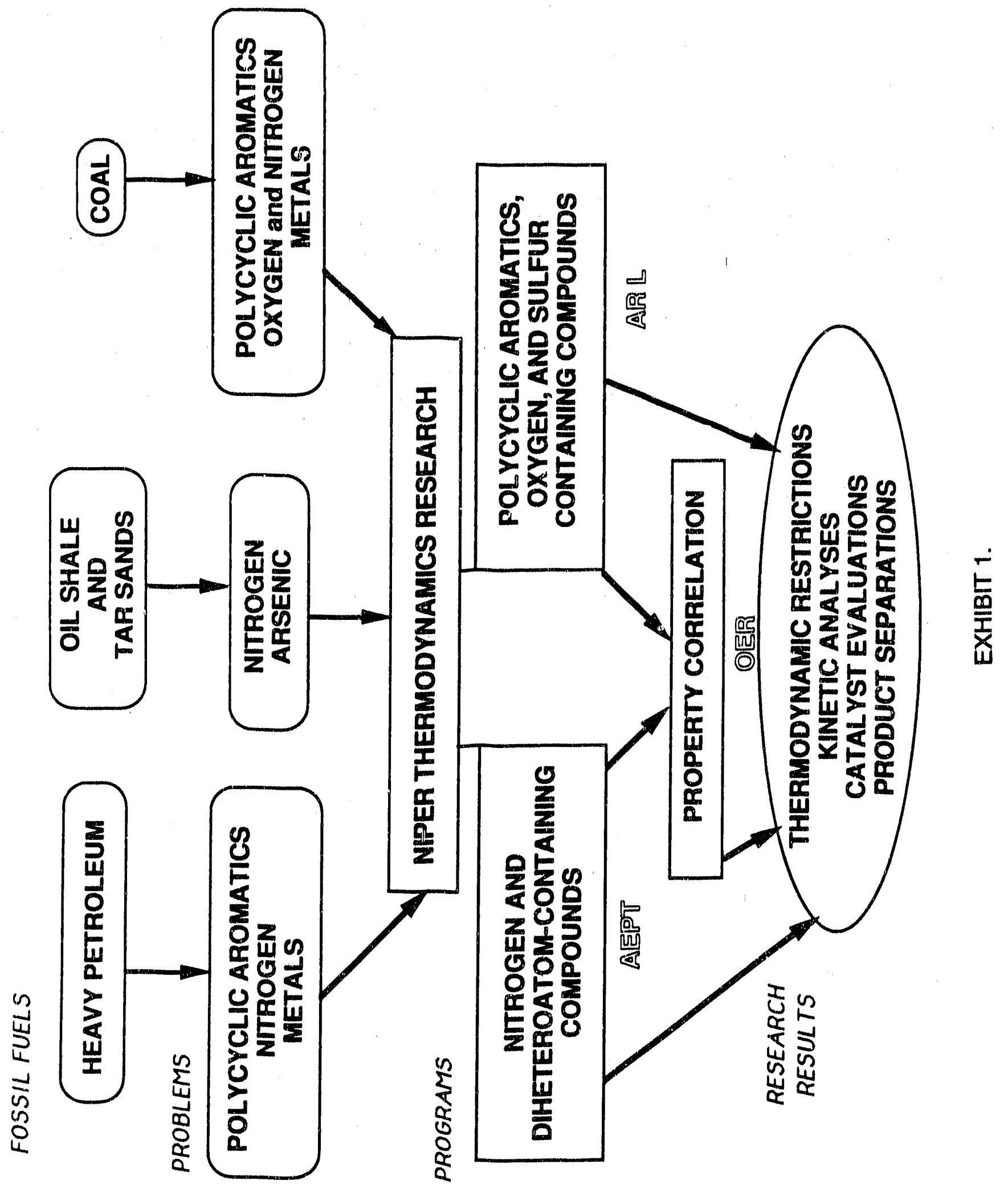


In FY91, measurements of seleoted thermodynamio properties of three 4-ring polycyollo aromatic nitrogen-containing compounds will be performed in conjunction with the estimation of the same properties using the data base derived in this project to date. If, as is expected, good agreement is obtained between the measured and estimated properties, a successful conclusion can be made to the nitrogen-containing compound section of the research. The property data base will then be sufficlent to enabis property estimations for all signiflcant nitrogen-containing structural types present in the alternate crudes.

In the diheteroatom-containing compound section of the research program, measurements will be made on three compounds. These will be selected on the basis of the assessment exercise completed in FY86 to meet the needs in extending the existing prediction and correlation methodology. A major criterion for selection will be the need for measurements on key compounds to determine the thermodynamic feasibility of pathways for upgrading diheteroatomcontaining heterocyclics using the minimum of hydrogen. The overall goal in this portion of the research program is the attainment of a property data base sufficient to enable property estimatlons for all significant diheteroatom-containing structural types present in the alternate crudes. Present estimation of the time-scale for completion of that task is FY93, assuming present funding and manpower levels.

Compounds chosen for study often are not available from chemical supply houses. Thus, an essential part of this work is the synthesis and purificailon of selected compounds through a subcontract with an Oklahoma State University group, which has unique capabilities and extensive experience in such preparations. Through close coordination of these efforts, the best compromises are made to select materials that are suitable for obtaining key information and which are possible to prepare in high purity.

\section{OBJECTIVES}

To measure, interpret, and correlate with molecular structure and polarity of molecules, precise and accurate values of thermodynamic propenties of organic nitrogen and diheteroatomcontaining compounds that occur in or are readily derivable from heavy petroleum and oll shale. The results enable the prediction of chemical equilibria for conceptual as well as current processes and the prediction of properties needed downstream from the reactor slages. 


\section{SCOPE OF WORK}

Iask 1. - Thermochemlcal measurements on oroanle nltrogen compounds. (Start date: October 1990. Completion date: September 1991.)

A. Preparation of three compounds of the required purity through the subcontract with Oklahoma State University. These will be selected on the basis of the assessment exercise completed in FY86 to meet the needs in extending the existing prediction and correlation methodology. Major criteria for selection will be the need for measurements on key compounds to determine the thermodynamic feasibility of pathways for upgrading nitrogen heterocyclics using the minimum of hydrogen, and to provide a stringent test of property-estimation techniques for nitrogen-containing compounds.

B. Make measurements of enthalpies of combustion, condensed phase heat-capacities (standard entroples), vapor pressures, and densities on selected key organic nitrogen compounds as equipment becomes available from queued experiments on these substances.

Iask 2. - Thermochemical measurements on selected diheteroatom. centainina compounds. (Start date: October 1990. Complotion date: September 1991.)

A. Preparation of three compounds of the required purity through the subcontract with Oklahoma State University. These will be selected on the basis of the assessment exercise completed in FY86 to meet the needs in extending the existing prediction and correlation methodology. A major criterion for selection will be the need for measurements on key compounds to delermine the thermodynamic feasibility of pathways for upgrading diheteroatomcontaining heterocyclics using the minimum of hydrogen.

B. Make measurements of enthalples of combustion, condensed phase heat-capacities (standard entroples), vapor pressures, and densities on selected key diheleroatom-containing compounds as equipment becomes avallable from queued experiments on these substances.

Task 3. - Thermodynamle analysis of nltroden removal in heavy petroleum and ell shale uporading. (Start date: October 1990. Completion date: September 1991.)

This task continues the evaluations (started in FY88) of the thermodynamic equilibria possible during the removal of nitrogen by the hydrotreating/hydrocracking of heavy petroleum and shale oll. In this financial year, thermodynamic analyses will be performed on model systems In an attempt to answer the three key questions posed above. In addition, studles will be made on the thermodynamic conditions necessary for the formation of nitrogen aromatic heterocycles in the alternate crudes. These studies will give insights into whether the processing conditions used currently for heteroatom removal actually produce more refractory heteroatom-containing compounds. Analysis of reaction networks for 3-ring materials will be included. 


\section{DELIVERABLES}

Dec 90 Topical report on the thermodynamic propenties of tetrahydro-9-methylcarbazole and 9-methylcarbazole.

Feb 91. Tupical report on the thermodynamic properties of 2-amino-biphenyl and the related compounds 2-methylbiphenyl and 2-hydroxybiphenyl.

Aug 91 Topical report detailing the thermodynarnic analyses performed in task 3 with emphasis on 3-ring compounds.

Sep 91 Status report on the research program summarizing data acquired, its utility, and an updated assessment for future work.

\section{PLAANED STAFFING}

Manager

Man-Years

Senior Chemists

a.1

Research Chemists

0.7

Research Physicist

0.3

Associate Chemist

0.3

Senior Experimentalist

0.3

Technical Support

0.3

Total

0.1

Project Leader

William V. Steele, Senior Chemist 
APPENDIX A. - CAPITAL EQUIPMENT REQUIREMENTS

\begin{tabular}{|c|c|c|}
\hline $\begin{array}{c}\text { Project } \\
\text { No. }\end{array}$ & Equipment & $\begin{array}{c}\text { Cost } \\
(\$ K)\end{array}$ \\
\hline \multirow[t]{4}{*}{ BE1 } & Core saw & 1.0 \\
\hline & Core Polisher & 2.0 \\
\hline & Apparatus for UV and Visible Photography of Cores & 5.0 \\
\hline & Cathodoluminescence Apparatus & 10.0 \\
\hline BE2 & Personal Computer & 6.0 \\
\hline BE3 & Personal Computer & 4.0 \\
\hline BEAB & Interfacial tensiometer (spinning drop) & 10.6 \\
\hline \multirow[t]{2}{*}{ BE5A } & High pressure electromagnetic viscometer & $3 . \dot{v}$ \\
\hline & Data acquisition system & 4.0 \\
\hline BE5 B & Data acquisition system & 3.0 \\
\hline \multirow[t]{2}{*}{ BE 9} & Pump for unsteady-state tests (2 each) & 19.0 \\
\hline & Corehoider for unsteady-state tests & 5.0 \\
\hline \multirow[t]{3}{*}{ BE11A } & Personal computer & 14.0 \\
\hline & Support equipment for new steamfiood model & 16.0 \\
\hline & Data backup system & 2.0 \\
\hline \multirow[t]{2}{*}{$B E 11 B$} & Thermal heat flux sensors & 2.0 \\
\hline & New steamflood physical model & 18.0 \\
\hline \multirow[t]{5}{*}{ BE 12} & High pressure core holder & 10.0 \\
\hline & Positive displacement pump (2 each) & 20.0 \\
\hline & Workstation for NMRI & 10.0 \\
\hline & $X$-Ray Tube & 300 \\
\hline & Total Base Program & 194.6 \\
\hline \multicolumn{3}{|c|}{ NIPER Support } \\
\hline \multicolumn{2}{|c|}{ Word processing-reproduction and/or computers } & 40.0 \\
\hline \multicolumn{2}{|c|}{ Salety } & 10.0 \\
\hline \multicolumn{2}{|c|}{ Maintenance } & 10.0 \\
\hline & Total NIPER Support & 60.0 \\
\hline
\end{tabular}

\#U.S. COVERNMENT PRINTUIC OFPICE: $1990 \cdot 561 \cdot 02920089$ 

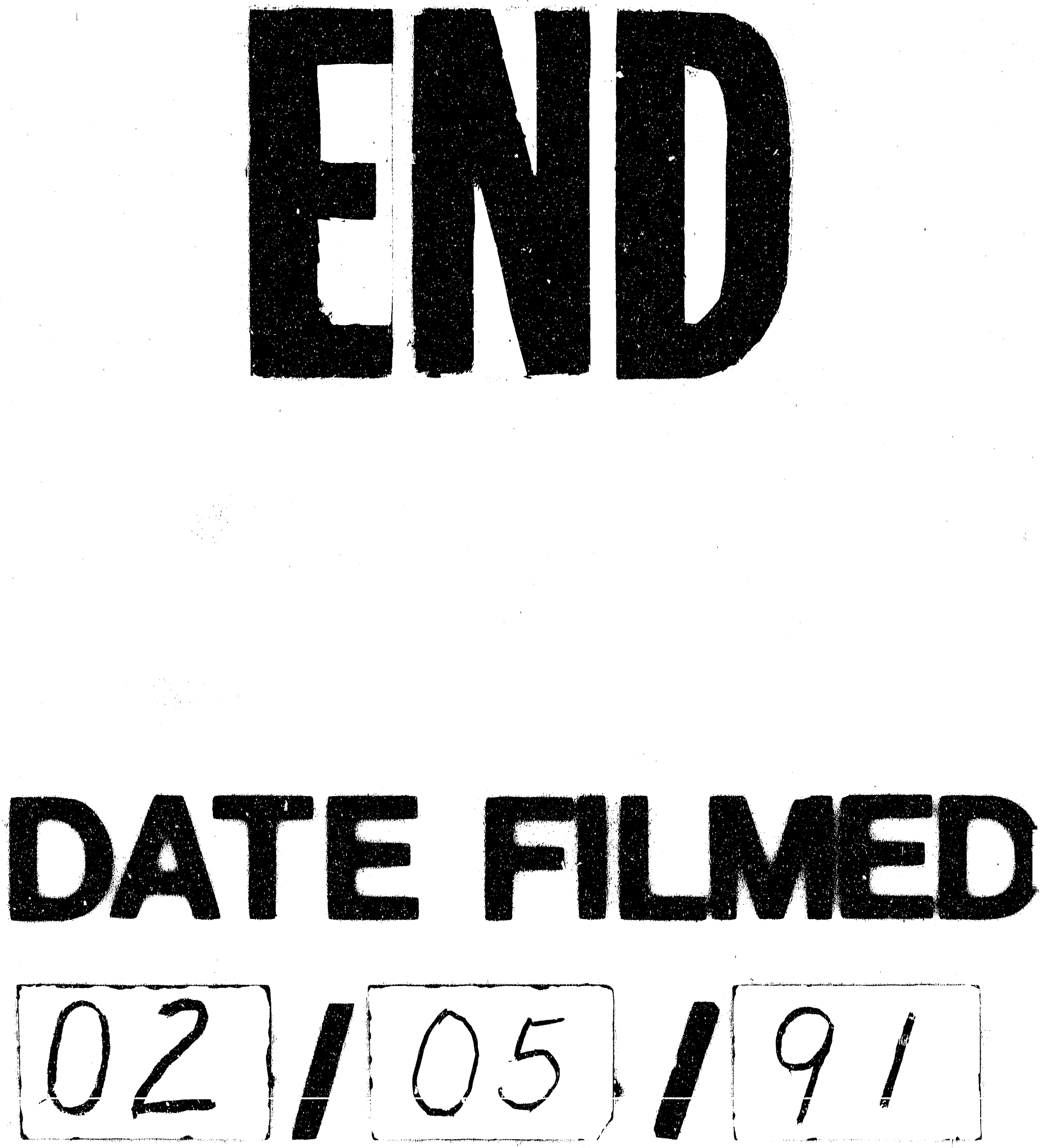
